Portland State University

PDXScholar

Fall 1-12-2018

\title{
Water Transport in the Lateral Line Canal of the Intertidal Fish Xiphister mucosus (Girard 1858) and Its Significance to Evaporative Water with Preliminary Observations of the Metabolic Consequences of Water Loss
}

Whitney Anne Gayer

Portland State University

Follow this and additional works at: https://pdxscholar.library.pdx.edu/open_access_etds

Part of the Animal Structures Commons, Biology Commons, and the Sense Organs Commons Let us know how access to this document benefits you.

\section{Recommended Citation}

Gayer, Whitney Anne, "Water Transport in the Lateral Line Canal of the Intertidal Fish Xiphister mucosus (Girard 1858) and Its Significance to Evaporative Water with Preliminary Observations of the Metabolic Consequences of Water Loss" (2018). Dissertations and Theses. Paper 4089.

https://doi.org/10.15760/etd.5973

This Thesis is brought to you for free and open access. It has been accepted for inclusion in Dissertations and Theses by an authorized administrator of PDXScholar. Please contact us if we can make this document more accessible: pdxscholar@pdx.edu. 
Water Transport in the Lateral Line Canal of the Intertidal Fish

Xiphister mucosus (Girard, 1858) and Its Significance to Evaporative Water with

Preliminary Observations of the Metabolic Consequences of Water Loss

by

Whitney Anne Gayer

A thesis submitted in partial fulfillment of the

requirements for the degree of

Master of Science

in

Biology

Thesis Committee:

Randy Zelick, Chair

Bradley Buckley

Susan Masta

Portland State University

2017 


\begin{abstract}
The lateral line canal system is a sensory organ found in all teleost fish that has a wide range of morphological variation. Variation in morphology may often be the result of evolutionary necessity where the need for function dictates form. Xiphister mucosus is an amphibious Stichaeid fish that inhabits the rocky intertidal zone of the northeastern Pacific Ocean. The rocky intertidal is considered an extreme environment where crashing waves and ebbing tides may require the specialization of adaptations for surviving the many abiotic stressors encountered there.

The lateral line trunk canal of Xiphister is regarded as unique among teleosts with multiple, branching, zigzag shaped canals that are morphologically complex. The $X$. mucosus canal was found to not serve as a mechanosensory organ, rather the findings presented here suggest a new role as a water transport organ. This may be an exaptation to help $X$. mucosus avoid desiccation during low tides when the fish remain upon the rocky shore and exposed to dehydration.

While emersed, Xiphister relies on cutaneous respiration as its primary means of aerial respiration.
\end{abstract}




\section{Acknowledgements}

I'd like to first give huge thanks to my thesis advisor, Dr Randy Zelick, for inviting me to join his lab, first as an undergraduate assistant then later as a graduate student. Thank you for your guidance, encouragement, and your many extremely patient editing sessions and explanations of archaic electronics. Thank you for supporting my ideas and research directions, your invaluable input, and having confidence in my abilities to see this project through.

I'd also like to thank my committee members, Dr Brad Buckley and Dr Susan Masta for all of their guidance through this process; your support, ideas, and feedback have been absolutely invaluable.

Felix Kaldenbach, I could not have done this without you! You were an incredible asset to both my (our) research and my rock climbing skills. I couldn't have picked a better research partner or friend to spend countless hours with on our collecting trips to the coast, waiting for fish to dry and the occasional adventure outside of the lab.

Thanks to my fantastic lab mates and friends, Mo Slusher, Nikko Merrell and Vinh Hua for becoming my academic family. Thank you for keeping me sane and reminding me it's ok to take a break, play board games, get dim sum, and have fun every now and then.

Thank you to Dr Annie Lindgren for giving me my first undergraduate lab research experience and pushing me to step out of my comfort zone and present our findings at the 2016 SICB conference. It was a great experience and a confidence booster, which help to solidify my determination to move forward with my academic career. 
I'd like to give a special thanks to Evonne Mochon-Collura and Jessica Hill of the Oregon Coast Aquarium; thank you for generously taking in my specimens so they can continue to teach others about what incredible little animals they are while getting to live out the rest of their lives in the lap of luxury.

Thanks to Andrew Mcculloch for being my rock despite the distance, I'm grateful every day that you're a part of my life and I can't wait for the adventures to continue!

My dog Yuki, you will never read this but I hope you know how guilty I feel about all the long hours and late nights of work and that you are a very, very good girl.

Finally I'd like to thank my family who have always encouraged me to achieve my goals, and who taught me to love and respect all living things big and small from the very beginning. You have been a limitless fount of love and support and I absolutely could not have accomplished this without you! 


\section{TABLE OF CONTENTS}

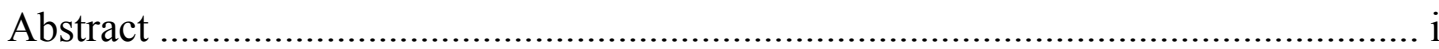

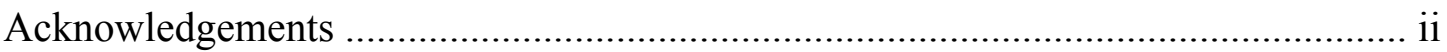

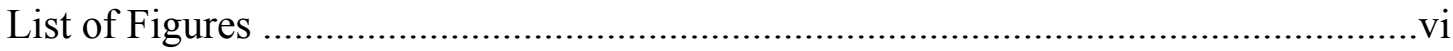

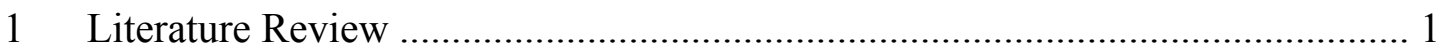

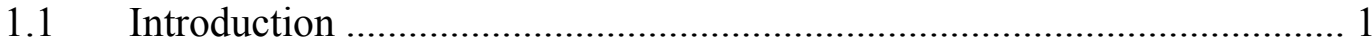

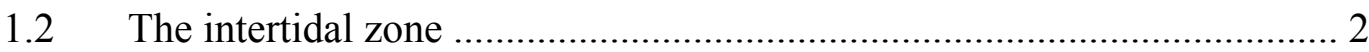

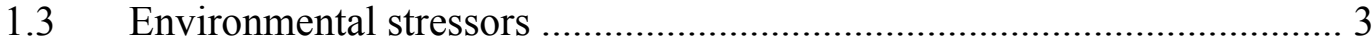

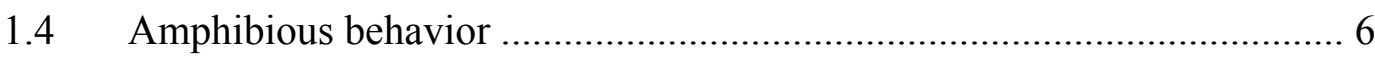

1.5 Sensory modification for amphibious life ……………………………...... 11

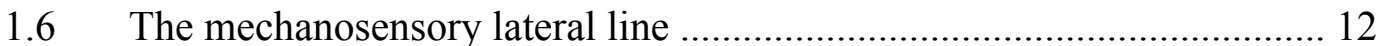

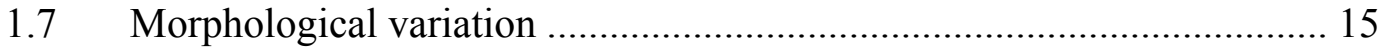

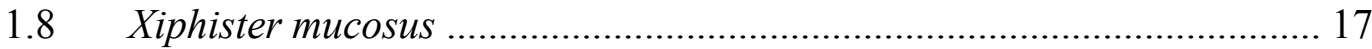

2 Water Transport in the Lateral Line Canal of the Intertidal Fish Xiphister mucosus (Girard 1858) and its Significance to Evaporative Water Loss ......... 23

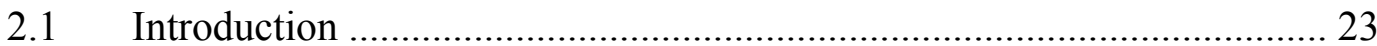

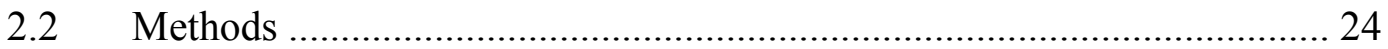

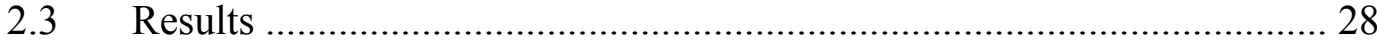

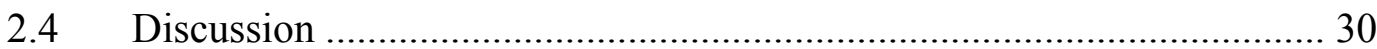

3 Preliminary Observations of the Metabolic Consequences of Water Loss in Xiphister mucosus (Girard 1858) .................................................................... 35

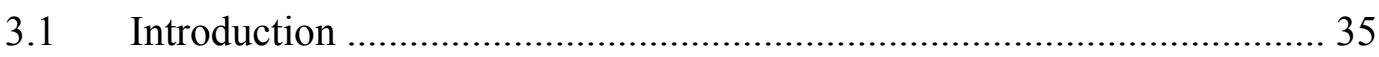

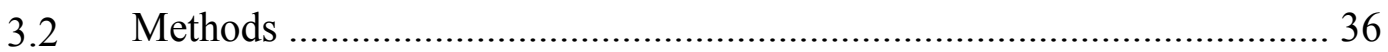




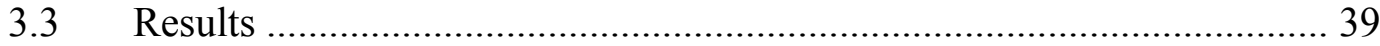

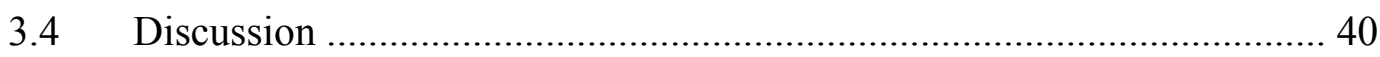

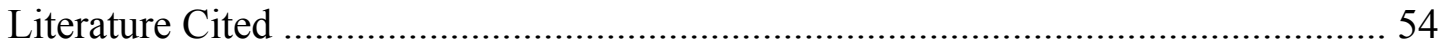




\section{LIST OF FIGURES}

Fig. 1 Diagram of Xiphister lateral line canal ................................................. 42

Fig. 2 Canal water transport setup .................................................................. 43

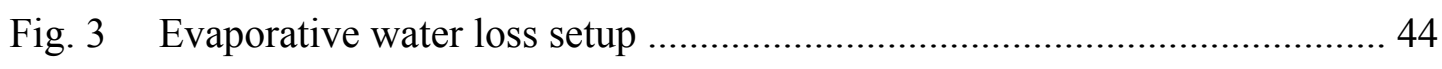

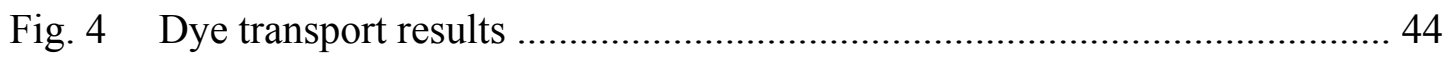

Fig. 5 Water flow rates in the lateral line canals of three fishes ........................ 45

Fig. 6 Water flow rates in the lateral line canal of Xiphister mucosus ................ 45

Fig. 7 Evaporative water loss results all fish, all conditions ............................. 46

Fig. 8 Xiphister vs. Anoplarchus: wrapped with tail immersed ......................... 47

Fig. 9 Evaporative water loss results all means .......................................... 48

Fig. 10 Xiphister in a metabolic chamber .................................................. 49

Fig. 11 Xiphister in a partitioned metabolic testing chamber ........................... 49

Fig. 12 Oxygen consumption rates: flat vs. raised ...................................... 50

Fig. 13 Oxygen consumption rates: head vs. trunk ..................................... 51

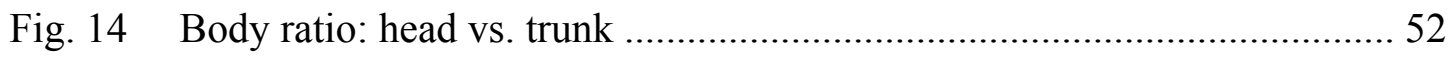

Fig. 15 Oxygen consumption rates: blocked vs. unblocked ............................. 53 


\section{WATER TRANSPORT IN XIPHISTER MUCOSUS}

\section{Literature Review}

\subsection{Introduction}

Some animals are adapted to relatively harsh environments including many species of fish. As of June 2017, there are more than 34,000 described species of fishes, with hundreds more being described each year. This places fishes in the majority of all vertebrate diversity with their species numbers making up more than half of vertebrate species (Eschmeyer and Fong, 2017). Fish are found in a nearly all aquatic habitats across the earth (Ali, 2013). This includes the deepest living vertebrates - two species of Liparidae (snailfish) found at depths exceeding $8075 \mathrm{~m}$ in the Mariana Trench where extreme pressure and cold $\left(4^{\circ} \mathrm{C}\right)$ are the major abiotic factors driving evolution (Linley et al., 2016; Eastman, 2017). The deepest dwelling freshwater fish are found in Siberia's Lake Baikal; a group of sculpin of the group Abyssocottidae found as deep as 1,600 m (Sideleva, 1996). On the opposite extreme, we find Triplophysa stolickai - a species of stone loaches found at the highest $(5,200 \mathrm{~m})$ elevations for freshwater fish (Kottelat, 2012; Wang, 2015). Fish are found deep in caves where they have become totally blind (Astyanax mexicanus, Cryptotora thamicola) (Jeffery, 2003) and have been observed scaling subterranean waterfalls (Chaetostoma microps, Cryptotora thamicola) (Vidthayanon, 2002; Hoese, 2015). Some fish, such as Lepidosireniformes, Ceratodontiformes, and many Cyprinodontiformes have even evolved to thrive in vernal pools that dry up either seasonally or even for years at a time (Podrabsky, 1999; Nelson, 2016). Other fish, such as those in the family Nototheniidae can survive the coldest habitable waters of the Antarctic where temperatures can get as low as $-1.86^{\circ} \mathrm{C}$ (Hoffman 


\section{WATER TRANSPORT IN XIPHISTER MUCOSUS}

et al. 2000) while one population of Alcolapia grahami has been recorded living in a hot spring with temperatures exceeding $40^{\circ} \mathrm{C}$ (Wood et al. 2016). There are fish that can tolerate broad ranges of abiotic factors: eurhyhaline fish can tolerate a broad range of water salinities, eurythermal fish are able to tolerate a broad range of temperatures, and euryoxic are able to tolerate a broad range of oxygen concentrations (Wootton, 2012). Some fish, like Gillichthys mirabilis are eurhyhaline, eurythermal and euryoxic (Doneen, 1976; Gracey et al. 2001; Buckley \& Hofmann, 2002).

Within every environment that fish have come to inhabit (extreme or not) are selective pressures that have pushed fish to evolve an incredible diversity of morphology, physiology, and behavior (Wooten 2012; Ali, 2013; Nelson, 2016).

\subsection{The Intertidal Zone}

One interesting environment that demands of its inhabitants the ability to survive in a broad range of conditions is the ocean's intertidal zone. The intertidal or littoral zone is the environment defined by the portion of ocean shoreline affected by the tides. It is broken up into different vertical zones based on the organization of species communities found there. The slope of the shore, type of substrate, exposure to wave action, and the range of tides, which varies by location and season, are all factors that determine the makeup of the communities able to inhabit each of the zones. The supralittoral (or upper intertidal zone) is the shore region only submerged during the highest tide and is home to hardy organisms that can survive with minimal moisture such as lichens, cyanobacteria, some molluscs and isopods. The infralittoral fringe (or lower intertidal) is exposed only briefly during the height of the lowest tides and is home to organisms adapted to a mostly 


\section{WATER TRANSPORT IN XIPHISTER MUCOSUS}

aquatic existence. Below the infralittoral is the sublittoral (or subtidal zone), which no longer faces exposure to air and extends to the edge of the continental shelf. Then there is the midlittoral or middle intertidal zone that sits directly below the supralittoral. It is in the midlittoral that we see the greatest abiotic fluctuations due to being submerged and exposed during the course of daily tides; it is also the zone that we see the greatest diversity and biomass of the intertidal zone (Stephenson \& Stephenson 1950). Here, when the tide recedes pools of seawater are isolated from the surrounding ocean, becoming temporary microcosms that are subject to environmental stressors not often faced in deeper intertidal zones or at all in the open ocean. The biotic and abiotic elements that influence the intertidal environment can change substantially throughout each day and also seasonally with the only constant being the ebb and flow of the tides.

\subsection{Environmental Stressors}

Organisms that inhabit these zones must be able to tolerate a number of environmental stressors, often occurring simultaneously. At the ever-changing water line, crashing waves create a turbulent and turbid environment; the force of wave shock can crush organisms or drag them out to open water (Turner \& Small, 2002). Since the water can become very shallow, reducing its light filtering capabilities, UV damage can cause molecular lesions known as thymine dimers in DNA, or highly reactive and damaging oxygen free radicals (Turner \& Small, 2002). During low tide, organisms in shallow tide pools and on the exposed shoreline face thermal stress that deeper waters would otherwise dissipate. The smaller volume to larger surface area ratio of a tide pool makes 


\section{WATER TRANSPORT IN XIPHISTER MUCOSUS}

it a relatively unstable habitat and thus prone to changes in temperature caused by ambient air temperature.

Increased temperatures can drive a host of interconnected stressors. Abiotically, higher temperatures decrease gas solubility and increase water evaporation, which concentrates salinity and water pollutants. This also decreases the size of the habitat, which may cause an increase in competition for food and shelter, and also increase predation (Horn \& Martin, 2006; Martin, 2014). Biotically, thermal stress can be particularly devastating as temperature controls all chemical reactions and therefore all biological function and physiology (Somero, 2002). Temperature disrupts macromolecule structures. Misfolded proteins may cause irreparable damage and demand the energetically expensive formation of heat-shock proteins; proteins beyond repair must be degraded and replaced, also at an energetic cost (Hill et al. 2004; Buckley, Somero). Altered membrane viscosity may lead to in high temperatures excess fluidity and the break down of marginal stability and even cellular structure. This is particularly dangerous when nerve cells begin to break down, releasing neurotransmitters, with no means of controlling the nerve firing. In cold temperatures membranes may form a rigid gel, ceasing to be fluid and thus halting cellular function. Restructuring membranes by building saturated or unsaturated lipid side chains, altering the head groups, or inserting cholesterols into the membrane bilayer may help to mediate the thermal stress induced alteration of fluidity but it too is an energetically costly process (Hazel, 1995; Hill et al. 2004). Protein-enzyme interactions are also temperature dependant. As temperatures rise, enzyme affinity decreases requiring a greater amount of protein substrate for whatever 


\section{WATER TRANSPORT IN XIPHISTER MUCOSUS}

reaction to continue occurring at the necessary, physiologically relevant rate, making it more difficult to control and adjust on the fine scale necessary to maintain homeostasis (Hill et al. 2004).

Because increased temperatures decrease gas solubility in water (Henry's law), this can hasten hypoxic events in pools that may already have high respiration demands from organisms taking refuge in the isolated pools during the course of the tide. Increased temperatures also have the biological effect of decreasing the oxygen affinity of heme the oxygen-binding component of most animals' blood cells. Reduced blood oxygen leads to the inability of organisms to remove carbon dioxide, the build up of which lowers blood $\mathrm{pH}$, and as the blood becomes more acidic this leads to the Root Effect - the acidity leads to the heme having an even greater reduction in oxygen affinity (Hill et al. 2004). Not only can hypoxic events lead to the suffocation of organisms unable to meet their metabolic demands, the replacement of dissolved oxygen with carbon dioxide from respiration may create hypercapnic conditions resulting in a drop in $\mathrm{pH}$ creating an acidic environment (Davenport \& Woolmington, 1981; Horn \& Martin, 2006). This may be especially problematic at night when plants and algae are consuming oxygen instead of releasing it (Bridges, 1993). Acidification has been shown to disrupt olfactory cues making fish unable to recognize predatory fish as well as increasing the attraction to predatory fish (Dixson, 2010). Alternatively, depending on the community makeup of the temporary microhabitat, warmer water may drive photosynthetic oxygen production in algae and aquatic plants leading to a rise in $\mathrm{pH}$ turning the water more basic. 


\section{WATER TRANSPORT IN XIPHISTER MUCOSUS}

Fluctuating salinity levels may also pose a problem for intertidal organisms. Heavy rains and the resulting runoff, and/or the shifting of estuarine freshwater may lead to hyposaline conditions while evaporative water loss in tide pools may result in hypersaline conditions. Due to these potential conditions, organisms must be equipped to maintain osmotic balance of both blood and intracellular volumes.

\subsection{Amphibious Behavior}

One way to avoid the host of stressors that regularly occur in extreme environments such as the intertidal zone, estuaries, or vernal pools is to literally avoid them and take up an amphibious existence. It is in tide pools as well as estuaries and mudflats that are subject to temporary hypoxic events that it is believed the vertebrate transition from aquatic to terrestrial existence evolved (Bridges, 1988; Sayer \& Davenport, 1991; Graham, 1997; Martin \& Bridges, 1999; Horn \& Martin, 2006; Martin, 2014).

Amphibiousness is the ability to inhabit (at the very least, tolerate) both aquatic and terrestrial environments. Since the first appearance of air breathing fish during the Paleozoic it is estimated that it has evolved between 38 and 67 times and more than 370 fish species from 49 families in both freshwater and marine environments are amphibious (Graham, 1997; Graham \& Lee, 2002). Those Paleozoic amphibious fish were the first vertebrates to utilize aerial respiration and it is this group that eventually gave rise to the terrestrial tetrapods (Graham, 1997).

Amphibious behavior is not unusual in the intertidal zone - over 70 species of teleosts from 12 families are known to spend at least part of their lives emersed from water (Bridges, 1988; Sayer \& Davenport, 1991; Graham, 1997; Martin \& Bridges, 1999; Horn 


\section{WATER TRANSPORT IN XIPHISTER MUCOSUS}

\& Martin, 2006; Martin, 2014). In their reviews of variation among amphibious intertidal fish, Martin \& Horn (1998, 2006; Martin, 2014), describe the three general types of amphibious fish emergence: passive remainers, active emergers, and skippers. Skippers are active as terrestrial fishes, emerging frequently (even with optimal water conditions), while the other two groups are mostly inactive upon aerial emergence.

Passive remainers, as the name suggests, take the "sit and wait" approach when the tide recedes. Intertidal fish opting to stay submerged that must shift into the lower littoral zones, which may force them out of protective habitats and make them vulnerable to predation. However, there is a trade-off, remainers may find themselves on the emersed rocky shoreline where they may be vulnerable to other hazards including terrestrial predators, desiccation and thermal stress.

Active emergers are more likely to be found in tide pools where, when faced with stressors such as hypoxia or hypercapnia, they will choose to leave their no longer comfortable tide pool in order to find one with more suitable physiochemical parameters (Martin \& Horn, 1998, 2006; Martin, 2014).

It is generally accepted that amphibious behaviors have primarily been driven by the need to adapt to hypoxic conditions (Packard, 1974; Romer 1967; Randall et al., 1981). The partial pressure of oxygen in air is much greater than that of water so even under normoxic conditions, respiration is more energetically costly for organisms that use water as a respiratory media that those that use air (Graham, 1997).

However, with air breathing having evolved multiple times independently throughout the adaptive radiation of fish, it may be possible there have been several circumstances under 


\section{WATER TRANSPORT IN XIPHISTER MUCOSUS}

which amphibious evolution occurred. In the 1991 review by Sayer \& Davenport, they outline a number of biotic and abiotic pressures (and combinations thereof) that may have driven the evolution of the facultative use of air breathing beyond hypoxia. Certainly in an isolated system (i.e. a tide pool cut off from the ocean) there are the many abiotic stressors discussed above, often occurring simultaneously, that may lead to water conditions poor enough to push evolution toward amphibiousness. But what about areas where the receding tides don't create tide pools, such as some rocky intertidal shores where temporary hypoxic events are not occurring? Sayer \& Davenport suggest that in such cases (aside from accidental strandings) it is more likely biotic factors such as predation, competition and resource availability may have driven amphibious fish evolution.

No matter the particular environment or potential evolutionary driver, amphibious fish, both freshwater and marine, must still be able to adequately exchange gases by one means or another, and there are a number of morphological specializations allowing them to utilize bimodal respiration. These are referred to as air-breathing organs (ABO's), and some taxa are known to use multiple types simultaneously. Two of the earliest known aerial respiration adaptations are the lung and respiratory gas bladder - these have evolved independently several times and from different points of morphogenesis (Graham, 1997; Perry et al., 2001; Daniels, 2004). These are thought to be the structures that allowed Paleozoic fish to begin the transition to non-aquatic environments (Graham, 1997; Graham 2006). Today, only the three orders of lungfish as well as the Polypteriformes (bichirs and ropefish) use lungs. In more derived teleosts, we see 


\section{WATER TRANSPORT IN XIPHISTER MUCOSUS}

methods for aerial breathing that include the use of other epithelial surfaces of the body. Respiratory surfaces must be are highly vascularized and thin so gases may diffuse freely across the membranes (Hill 2004). Around the head this includes the buccal cavity, pharynx, pouches adjoining to the pharynx, the operculum, brachial surfaces and diverticulae as well as modified gills - in general, gills collapse when removed from water (Graham, 1997). Further down the digestive tract, the esophagus, stomach and intestines may be used as surfaces for gas exchange; even the pneumatic duct that connects the gas bladder to the digestive tract may be used. Finally, the skin may be used for cutaneous respiration (Graham, 1997).

Amphibious fish must also be able to tolerate dehydration stress. This occurs in a variety of ways. Some species respond to unfavorable conditions by falling into a state of metabolic dormancy where activity halts and the need for both oxygen and water slows or is arrested entirely, allowing the fish to simply wait until conditions are more compatible to that species' requirements for active life. Lepidosireniformes (the African and South American lungfish) will survive their respective dry seasons by burrowing into the mud and decreasing their metabolic rate and remaining in a state of aestivation until the rains return (Delany, 1974). The lungfish will secrete a cocoon of protective mucous, a tactic similar to the aquatic amphibian, Siren intermedia, which was found to significantly slow desiccation (Reno et al. 1972). The annual killifish (Cyprinodontiformes), live in seasonal vernal pools found in typically dry savannah or desert habitats; as these dry up, the adults perish leaving their eggs behind to wait for the next opportune condition to hatch. During embryonic development anoxia and desiccation will induce the eggs to go into a state of 


\section{WATER TRANSPORT IN XIPHISTER MUCOSUS}

diapause dormancy, a depressed metabolic state in which they may remain as such for up to years at a time (Podrabsky \& Hand, 1999). These relatively extreme coping behaviors are found in freshwater fishes that must deal with extremes in seasonal variation. In the intertidal where the duration of exposure to the threat of desiccation occurs on a much shorter time scale, less drastic coping mechanisms are observed. Intertidal fishes found on the rocky shoreline will use physiological methods to avoid desiccation such as increased mucus production or behavioral methods stemming from thigmotaxis. Thigmotaxis is the response to touch stimulus causing fish to seek appropriate shelter such as in under-rock crevices where the microclimate may be more ideal, cluster with other fish reducing the surface area from which water may evaporate, or rolling to collect moisture on the skin from surrounding surfaces (Gibson, 1986; Martin \& Horn, 2006). While amphibious fish may be able to avoid harsh aquatic conditions they may encounter, hazardous temperatures may be more difficult to avoid. Some studies suggest that overheating contributes to a greater, if not the majority, number of mortalities than desiccation alone (Gordon et al. 1969 \& 1970). With very few exceptions all fish are poikilotherms, i.e. the environmental temperature dictates their internal temperature. As such, exposure to increases of temperature may cause spikes in metabolism that, when already faced with hypoxic conditions often occurring in tide pools or mudflats, may lead intertidal fish to suffocate if they lack enough oxygen for sufficient respiration. This may be particularly true of amphibious fishes that rely on cutaneous respiration where gas exchange may be hindered by mucous, scales, thicker skin, limited ventilation, and/or the demanding metabolic rate of active skin cells (Graham, 1997). It may be that intertidal 


\section{WATER TRANSPORT IN XIPHISTER MUCOSUS}

fishes rely on evaporative water loss for its cooling effects; however, in some temperate zones this thermal stress appears to be less of an issue than desiccation. In one two year study Barton (1985) recorded temperature data for the micro habitats beneath rocks in Yaquina Bay, OR, known to be a preferred low tide habitat of a number of fish species. This study showed temperatures ranging from $4^{\circ} \mathrm{C}$ during winter low tides to $24^{\circ} \mathrm{C}$ during summer low tides. However, Barton's (1985) and our own informal measurements showed a much more stable thermal range in the insulated, under-rock habitats varying no more than $2^{\circ} \mathrm{C}$ during the low tide period in both winter and summer.

\subsection{Sensory Modification For Amphibious Life}

In some cases, there are sensory adaptations to life in both an aquatic and terrestrial world. For example Anableps microlepis the "four-eyed fish" is an estuarine, surface feeding fish with eyes modified to see both above and below water at the same time. Its partitioned pupil and asymmetric lens allows the eye to compensate for differing light and refraction qualities in the air and water (Schwassmann, 1965; Sivak, 1976). One sensory system that is vulnerable to an amphibious life style is the mechanosensory lateral line. This mechanosensory lateral line's sensory surface is partially exposed, which may be problematic at is relies on proper hydration and ion balance to function and, as mentioned earlier, in the intertidal organisms are often subject to salinity fluctuation. The intertidal is a turbulent environment with a great deal of hydrodynamic stimulus and "noise" - modifications may help fish to offset this "loud" environment. Finally, as the lateral line canal is a sensory system for aquatic environments and as such it offers little 


\section{WATER TRANSPORT IN XIPHISTER MUCOSUS}

benefit to amphibious fish when emersed from the water and dehydration may possibly have negative effects on the delicate sensory cells, however, this has been little studied.

\subsection{The Mechanosensory Lateral Line}

The lateral line mechanosensory system is a highly conserved trait found in all aquatic vertebrates - fishes and amphibians (at least in their larval stage - many amphibians lose this trait upon metamorphosing into their terrestrial form) (Schwartz, 1974; Coombs et al. 1988; Northcutt, 1989; Webb 1989). This sensory system allows organisms to perceive weak water flow and pressure gradients, which in turn permits prey/predator detection, fish schooling behavior (Partridge and Pitcher, 1980; Bleckmann, 1986), intraspecific communication, and spatial orientation. (McCormick, 1989; Webb, 1989; Bleckmann \& Münz, 1990, Bleckmann \& Zelick, 2009). The canal system acts as an accessory organ to small, functional units called neuromasts: hair cell sensory structures activated by the mechanical force of fluid movement within the canal. Neuromasts are found in a set of cephalic canals, trunk canals, and/or they can be embedded within the skin and not in canals. When located in a canal, the neuromasts are nearly always located between two pores, though there are some exceptions such as when a membrane covers the canal or if it simply lacks pores (Coombs et al. 1988). In the canal the effective stimulus of the neuromast is water acceleration near the fish leading to a pressure differential at adjacent canal pores. The canal system containing neuromasts is believed to have evolved early in vertebrate existence and is thought to have formed from a series of placodes - epithelial structures that may differentiate into sensory neurons - in grooves on the body of early gnathostomes (Northcutt, 1989; Park, 2010). Even still, some fish have canals that are 


\section{WATER TRANSPORT IN XIPHISTER MUCOSUS}

little more than grooves in the skin, though the canal can be entirely or partially enclosed (Coombs et. al., 1988). Those in the skin are "superficial" or "freestanding" neuromasts and serve as bulk-flow water velocity detectors (Coombs et al. 1988; Webb, 1989, Bleckmann, 1994, Montgomery 2000, Englemann 2000).

The hair cell is an ancient sensory organ found in all vertebrate classes, with evidence (such as their presence in the class agnatha) suggesting they evolved in the earliest vertebrates or possibly, as speculated by Coffin et al. (2004), in the chordate ancestors of the earliest vertebrates. Neuromasts are comprised of bundles of several to typically some hundreds of hair cells (Bleckmann and Zelick, 2009; Klein et al. 2012) protected by a gelatinous cap or "cupula," that sits atop the epithelium that house the sensory cells (Flock, 1971). The cupula is made of tubule compartments that create an ion rich environment for the hair and that extends into the canal (Flock, 1965; Russel \& Sellick, 1976). There is little overall difference in morphology of the hair cells across the vertebrate classes - the hair cells in neuromasts are quite similar to those in mammalian auditory systems (Coffin et al. 2004; Smith, 2008). The hair cell is a displacement mechanotransducer comprised of a basal body that has on one end a cuticular plate extending from which are rigid bundles of actin filaments called stereovilli in a step-wise progression that terminates at the tallest part of the structure - a bundle of microtubules called the kinocilium. The stereovilli are each linked to both the next closest shorter and taller neighboring bundles by a spring-like polypeptide filament called the tip link. Bending the hair bundle by nanometer amounts leads to a change in neurotransmitter release. The hair cell is biased so that any displacement away from the rest position 


\section{WATER TRANSPORT IN XIPHISTER MUCOSUS}

causes a response, i.e., there is no threshold - this may allow directional sensitivity

(Flock, 1965). As lateral displacement bends the bundles the bias causes greater distance between the tops of the stereovilli creating tension in the tip links, which gates open channels allowing for the influx of ions from either the endolymph (in the inner ear) or the cupula (in teleost neuromasts) into the cytoplasm of the cell (Coombs et al. 1988; Smith, 2008). One of the most significant differences between inner-ear hair cells and neuromast hair cells is the medium surrounding the stereovilli. In the ear, a viscous fluid known as endolymph surrounds hair cells. Endolymph is rich in potassium, which is actively transported into the endolymph and low in sodium, which is transported out (Konishi et al., 1978). The cupula surrounding the hair cells of fish and amphibians, while "freely permeable" to ions, was found to mostly contain potassium and chloride ions (Russel \& Sellick, 1976). These charged ionic compositions and the electrochemical gradient they create are required for depolarization to occur. This influx of ions depolarizes the cell causing a release of neurotransmitters at the base of the hair cell, and triggering action potentials in the cell's associated primary afferent neuron. The more the bundle is flexed in one direction, the greater the frequency of the neural impulses. If flexed in the opposite direction, the frequency decreases (Smith, 2008).

Because the neuronal response relies entirely on electrochemical gradients created by the sequestered ions, it is imperative that some form of homeostasis be maintained. This may well prove to be a challenge in the intertidal environment where salinity fluctuation and desiccation are commonly encountered. Unlike the well-protected hair cells of the inner ear, the lateral line canals are filled with fluid similar to, if not in fact, seawater and 


\section{WATER TRANSPORT IN XIPHISTER MUCOSUS}

therefore, the neuromasts may be subject to inclement environmental changes (Liddicoat \& Roberts, 1972). However, seawater does not "free-flow" through the canals and at the microscopic scale boundary layer conditions exist where viscous forces dominating over turbulent forces may maintain a protective environment.

The freestanding neuromasts respond to velocity and to bulk water flow. A hair cell in a canal responds to acceleration and has the ability to differentiate between bulk-flow and water movement created by predators or prey (Bleckmann et al. 1989; Coombs \& Janssen, 1989). Much like auditory hair cells, neuromasts are displaced by wave frequencies measured in hertz $(\mathrm{Hz})$, and have sensitivity at the lowest frequency of hair cell reception (Coombs \& Janssen, 1989). Fish have been shown to be able to register, with their lateral line canal system, frequencies from $0-150 \mathrm{~Hz}$; however, different species have been shown to have different "best frequency" ranges dependent on the traits of their physical environment and the predators/prey they encounter (Wilcox, 1987; Bleckmann, 1987; Bleckmann et al. 1989; Coombs \& Janssen, 1989). For example, Bleckmann et al. (1989) showed that despite the variation in LLC system morphology the surface feeding fishes Aplocheilus and Pantodon are able to distinguish the wave movement created by their insect prey $(>50 \mathrm{~Hz})$ from other surface wave sources such as lower frequency $(<50 \mathrm{~Hz})$, wind generated waves.

\subsection{Morphological Variation}

The wide range of morphological variation of lateral line canal systems among Osteichthyes is believed to be a necessity of function. Differences in morphology, such as diameter and shape of the canal; size, shape, number and placement of neuromasts; canal 


\section{WATER TRANSPORT IN XIPHISTER MUCOSUS}

innervation; and the distribution of pores and neuromasts are believed to allow for different sensitivity and response properties (Dijkgraaf, 1967; Coombs et al. 1988; Coombs \& Janssen, 1989).

Coombs et al. (1988) describes six distinct patterns of trunk canal morphology types and five additional variations that can be found within those morphologies. The most common morphology found is a set of cephalic canals with a single, complete, fluid-filled, sub-dermal tube of bone or modified scales, running the midlateral length of the animal's trunk (on both sides), terminating at the caudal peduncle, with pores opening the canal to the external environment. This is considered the "standard" trunk canal. Other morphology types include canals that are incomplete that do not run the full length of the body, disjunct canals that have a break in the canal, multiple canals (up to 5 on either side), or fish may lack trunk canals entirely. Canals may be straight, zig-zag shaped, arched, or branched, and there may be variations of placement, with the canal either more ventrally or dorsally placed (Coombs et al. 1988; Webb, 1989). Neuromasts vary in size, shape, placement within the canal, and may even be so large as to block the canal entirely (Dijkgraaf, 1967; Coombs et al. 1988). While Gray (1983) showed that the narrow canals of clupeids allow for velocity detection, Jansen (1997), suggests that wide canals found in Gymnocephalus cernuus (also common in deep sea fishes) is more sensitive for enhanced prey detection, may amplify prey signals and reduces noise from laminar flow.

Considering the variation found within canals across species, it is difficult to make broad generalizations regarding ability based solely on morphology. 


\section{WATER TRANSPORT IN XIPHISTER MUCOSUS}

\subsection{Xiphister mucosus}

One excellent model organism to study the effects of the harsh intertidal environment is the rock prickleback, Xiphister mucosus - a eurythermal, eurhyhaline, euryoxic, and amphibious fish (Evans, 1967; Horn \& Riegle, 1981; Daxboeck \& Heming, 1982; Barton, 1983; Haynes et al. 2009). Xiphister is a small, elongated (up to $58 \mathrm{~cm}$ ), teleost of the family Stichaeidae. While once considered to belong in the large, paraphyletic order Percifomes, Stichaeidae have been moved to the Suborder Zoarcidae of the order Cottiformes, which contains twenty families of sculpins, eelpouts, and their relatives (Wiley \& Johnson, 2010) This move was confirmed by both morphological evidence thirteen synapomorphies in the order, and additional three in the suborder (Imamaura \& Yabe, 2002)- and by molecular analysis (Smith \& Wheeler, 2004).

There are 35 genera and 70 species in the Stichaeidae (or Prickleback) family and of these, five species from three genera are known to be amphibious intertidal dwellers (Barton, 1985; Martin, 1993; Graham, 1997). Also within the Xiphister genus is Xiphister atropurpureus. Both of these species of Xiphister inhabit rocky intertidal zones from Alaska to Baja California (Eschmeyer \& Herald, 1983, Mecklenburg \& Sheiko, 2004). Both species dwell within the intertidal however, $X$. atropurpureus typically resides in deeper waters while $X$. mucosus is often found in the upper reaches of the midlittoral. At low tide, Xiphister will regularly remain above the waterline hiding amongst rocks and algae (Horn, Martin, \& Chotkowski, 1999). When an artificial tide was simulated in their lab, Horn and Riegle observed the Xiphister and other intertidal Stichaeids and Pholids, (both families within the superfamily Stichaeoidei (Radchenko, 2013)), will associate 


\section{WATER TRANSPORT IN XIPHISTER MUCOSUS}

with one another, presumably to minimize their individual surface area and to benefit from the groups collective mucus secretions. Anecdotally, we observed this behavior during our field collection, often finding individuals of multiple species heterogeneously clustered under the same shelter. Two of these species would become our control organisms: Anoplarchus purpurescens (Gill, 1861), the high-cockscomb prickleback, and Apodicthys flavidus (Girard, 1854), the penpoint gunnel. These species were chosen for their similar life histories to Xiphister and for the variation of trunk lateral line canal morphology they present. A. purpurescens has a single trunk canal while $A$. flavidus lacks one entirely (Gunther, 1861; Makushok, 1961). Both A. purpurescens and A. flavidus are included with Xiphister in the family Stichaeidae and they can each be found in association with Xiphister under rocks and algae during low tides.

During low tide when out of water Xiphister and other intertidal cohabitants are speculated to rely on cutaneous respiration or buccal pumping while exposed from the water, an exaptation to frequent exposure from water during which the efficacy of their gills is reduced (Daxboeck \& Heming, 1982, Horn \& Martin, 1999).

The lateral line canal of $X$. mucosus is often referred to as "highly unique" both in its multiplicity and in its branching. Only in fifteen families of teleost fish are there examples of species with such characteristics (reviewed by Clardy \& Hilton, 2015). Species with multiple, parallel canals are typically found in fish that live in topographically complex substrates. Instead of one trunk canal it is composed of three main trunk canals (Fig. 1) - the dorsolateral (DLC), the mediolateral (MLC), the ventral canal (VLC) and ventral canal loop (VLC-L), for a total of 7 canals (Clardy \& Hilton, 


\section{WATER TRANSPORT IN XIPHISTER MUCOSUS}

2015). Each of these canals is zigzag-shaped with branches (tubuli) extending for each point in the zigzag. All branches on each side of the body contain numerous pores but neuromasts are located only in the main canals of the DLC and MLC canals (Clardy \& Hilton, 2015).

As mentioned earlier, the multiple, branched canal morphology was postulated to increase the spatial resolution for detection of biological hydrodynamic events occurring in the turbulent intertidal environment (Webb, 1989). Bleckman and Münz (1990) tested the trunk canal system of $X$. atropurpureus; the results of this study showed that the peak sensitivity of $X$. atropurpureus is in the $100-150 \mathrm{~Hz}$ range and this is not significantly different than that of simple, single canal lined fish $(75-150 \mathrm{~Hz})(\mathrm{Münz}, 1989)$. However, their calculations lead them to the prediction that the multiple lateral line canals may increase the receptive field size in a hydrodynamically noisy environment. One frequently suggested theory regarding variation in lateral line canal morphology is that environmental hydrodynamic noise has played a crucial role in the diversification of the lateral line canal morphology (Webb, 1988). Dictyosoma burgeri (van der Hoeven, 1855), Xiphister mucosus (Girard, 1858), Xiphister atropurpureus (Kittlitz, 1858), and Pytichthys chirus (Jordan \& Gilbert, 1880), are four species in the stichaeidae subfamily Xiphisterinae that inhabit turbulent intertidal environments and all share the trait of having multiple, branched canals but unfortunately, few studies have focused on the function of their complex lateral line canal structures. One hypothesis suggests that the multiple lines may allow for a higher resolution in sensing hydrodynamic stimuli in a more turbid environment (Bleckmann \& Münz, 1990). Conversely, studies of Red Sea 


\section{WATER TRANSPORT IN XIPHISTER MUCOSUS}

blennies found that of the 5 species looked at, Alticus kirki, known to live at the highest point of the intertidal zone - a zone characterized by turbulence and crashing waves, had a significantly reduced lateral line system compared to the more aquatic species, such as Salarias fasciatus (Zander, 1972). So as often is the case in biology, there is no easy generalization.

The question of whether or not the multiple lateral line canals increase the receptive field size in a noisy environment was tested by Klein et al. (2013) using artificial constructed canals modeled after the zigzag and branched Xiphister lateral line canal morphology. Klein et al. (2013) were able to see an improvement over standard lateral line morphology in the signal-to-noise ratio, which could allow Xiphister the benefit of being able to discern important stimuli from the otherwise noisy intertidal environment. However, along with the improved signal-to-noise ratio, the researchers observed a decrease in spatial resolution. This lead to the speculation that the multiple canals may have evolved in order to compensate for that reduction with each subsequent canal restoring a portion of the resolution.

Unfortunately, physiological data on lateral line stimulus detection in Xiphister have not been consistent. While Bleckmann and Münz (1990) showed that the X. mucosus congener, $X$. atropurpureus, does in fact have a neural response to sub-surface water vibrations, this does not seem to be the case for $X$. mucosus. Using various extracellular recording techniques, Kaldenbach (2016) was unable to elicit a neuronal response to mechanical stimulation in any of the trunk canal lateral line nerves of $X$. mucosus. He was however able to elicit a response to thermal stimulus indicating active sensory 


\section{WATER TRANSPORT IN XIPHISTER MUCOSUS}

function of the nerve despite lacking mechanosense. While the two species of Xiphister are often written about almost interchangeably, in regard to at least their lateral line canal systems we feel more care should be given toward treating them as distinct entities.

There is also anatomical variation within the Xiphister multiple-lined canal system. Clardy et al. (2015) located neuromasts via histological sectioning in only the dorsolateral and mediolateral canals. Data from Kaldenbach (dissertation, 2016), using DASPEI staining and SEM imaging supports Clardy's findings. The loss of neuromasts in some canals and the apparent loss of sensitivity to mechanical stimulation (at least in $X$. mucosus) is surprising and suggests there may be an alternative role for the unusual branched canal system.

Horn \& Riegle (1981) compared five amphibious intertidal stichaeoid fish that, like Xiphister, passively remain on the rocky shore as the tide recedes. They showed each species studied has varying limits of tolerance for exposure from water with some species, particularly the larger Cebidichthys violaceus and X. mucosus, being able to survive losing up to $24 \%$ of their body weight via water loss. They also showed each species to have differing abilities to rehydrate upon re-immersion. They found some $X$. mucosus able to survive up to 36 hours (with the average being 23 hours) of exposure from water when held at $15^{\circ} \mathrm{C}$ with $95 \%$ humidity - conditions not unlike those found in the intertidal zone of their home range. When dehydrated along with other similar intertidal fish, weight-specific water loss and rehydration rates were highest in both species of Xiphister. These authors also showed that the control species used in the present study, 
WATER TRANSPORT IN XIPHISTER MUCOSUS

Anoplarchus purpurescens (the high cockscomb prickleback), exhibited the lowest rate of water loss (66\% less than Xiphister). It is possible the high levels of water loss experienced by Xiphister may require some adaptation to mediate desiccation.

During Felix Kaldenbach's dissertation research, we observed blood moving quickly through the canals of a dissected specimen. This led us to consider a new hypothesis: perhaps the multiple highly branched canal morphology may function as a specialized system for water transport. Based on this observation and our knowledge that $X$. mucosus lacks mechanosensory functionality of its complex lateral line canal system, is amphibious, spends potentially half of its life out of water, relies on cutaneous respiration while exposed from water, we believe the Xiphister lateral line canal was once a sensory system that over evolutionary time has been co-opted to serve an exaptive function - to move water across the body to assist in desiccation avoidance when above the tide line with minimal access to water. 


\section{WATER TRANSPORT IN XIPHISTER MUCOSUS}

\section{Water Transport in the Lateral Line Canal of the Intertidal Fish Xiphister mucosus (Girard 1858) and its Significance to Evaporative Water Loss}

\subsection{Introduction}

The rock prickleback, Xiphister mucosus is an amphibious, teleost, cottiform fish with the somewhat unique trait of multiple, branched lateral line canals. Xiphister inhabits rocky intertidal zones and during low tide they, along with a number of other cohabitating fish species, will remain above the waterline hiding in rock interstices or algae for many hours at a time. During this interval, up to twelve hours and twenty-five minutes (the time between high tides), Xiphister rely on aerial respiration (Horn \& Riegle, 1981; Barton, 1985; Martin 1995), and while Xiphister has relatively impermeable skin, evaporative water loss is a potential hazard (Evans, 1967). Kaldenbach (2016) found that the multiple trunk lateral line canals of Xiphister mucosus are non-functional as a mechanosensory organ. We believe instead, the primary functions of the Xiphister lateral line canal may be desiccation avoidance and rehydration assistance - a mechanism by which Xiphister is able to cope with the abiotic forces that dictate life in the intertidal zone. Our goal was investigate whether the lateral line influences the processes of dehydration and rehydration and to explore whether $X$. mucosus have a potential fitness advantage in terms of dehydration tolerance relative to other similar intertidal teleost species that inhabit the same environment with less complex lateral line canal structures. Our study shows when compared to species that lack a multiple, branched canal system, the $X$. mucosus lateral line canal exhibits: 1) efficient capillary action capabilities that the others did not, and 2) evaporative water loss was significantly $(\mathrm{p}<0.001)$ decreased, when positioned with the tail submerged in water and something to create an adhesive force 
WATER TRANSPORT IN XIPHISTER MUCOSUS

driving that capillary action. This suggests that the multiple branched canal system may play a key role in maintaining hydration during periods of exposure from the water. Assuming a mechanosensory function is the primitive condition for the trunk canal, this may be one of few examples of a sensory organ being co-opted for an entirely different function.

\subsection{Methods}

\section{Specimen Collection and Housing}

Twenty-six Xiphister mucosus $(13-45 \mathrm{~cm})$, fifteen Xiphister atropurpureus $(10-23.5$ $\mathrm{cm})$, twenty-four specimens of Anoplarchus purpurescens $(8.5-13.5 \mathrm{~cm})$ and six Apodichthys flavidus $(12-15 \mathrm{~cm})$ were collected by hand from Yaquina Bay (Newport, Oregon; 443' $\left.3.49^{\prime \prime} \mathrm{N}, 124^{\circ} 3^{\prime} 27.12^{\prime \prime} \mathrm{W}\right)$.

Since all fish used for this study are amphibious, collection occurred during low tides in a vertical range from $+0.0 \mathrm{~m}$ to $+1.0 \mathrm{~m}$ above the waterline by turning small boulders on the rocky shoreline and catching the fish by hand, often by sweeping the fish into nets. Fish were transported in polyethylene fish transport bags with saltwater and seaweed, in Styrofoam coolers with icepacks and aquarium bubblers for ventilation. They were housed in the saltwater facilities of the Department of Biology of Portland State University in a $190 \times 75 \times 45 \mathrm{~cm}$ tank at a temperature of $12{ }^{\circ} \mathrm{C}$, salinity $35 \mathrm{ppm}, 12 / 12 \mathrm{~h}$ light/dark cycle and were fed with blackworms (Lumbriculus variegatus) and ocean shrimp (Pandalus jordani). Rocks covered in sea lettuce (Ulva lactuca) were regularly brought in from the coast to provide cover and fresh algae for grazing.

\section{Immobilization}




\section{WATER TRANSPORT IN XIPHISTER MUCOSUS}

Fish were denied food for 24 hours prior to experimentation, then were transferred to a container with 1\% MS 222 (tricaine methanesulfonate; Western Chemical, Inc.) in seawater for initial sedation. Once unresponsive they were immobilized with an injection of pancuronium bromide $(0.25 \mu \mathrm{g} / \mathrm{g}$ bodyweight; Hospira, Inc.). Following experiments, fish were placed in partitioned enclosures within their "home" tank for monitoring recovery.

\section{Dye Transport}

Immobilized Xiphister were removed from the water and placed on their side, and all water was removed from the lateral line trunk canals by repeatedly applying paper towels to the fish skin. Methylene blue dye was dropped via glass capillary tube onto the skin at random points of the lateral line canal and observed to immediately spread out through the canal system. This process of spreading was clearly visible through the relatively transparent skin and was videotaped $(30 \mathrm{fps}, 1920 \times 1080$ pixels; EOS 550D Canon, Japan) mounted to a dissecting microscope (Olympus bh2-rfca microscope, Olympus Optical Co., Ltd., Japan) in place of the normal ocular using a custom fabricated adapter). Single frames of the video in time intervals of one second were cropped, background subtracted and converted to black and white on the base of an appropriate threshold. The same test was also carried out on goldfish (Carassius auratus), for comparison.

\section{Water Flow}

The flow rate of water through the lateral line canals of three similar species in the suborder Zoarcoidei (two Sticaeidae and one Pholidae) was measured. These species have overlapping distribution patterns in the rocky intertidal zone. Both non-Xiphisterene 


\section{WATER TRANSPORT IN XIPHISTER MUCOSUS}

species were chosen for their similar body shape and life history, but with differing lateral line canal morphology. Anoplarchus purpurescens has the typical single canal morphology most commonly seen in teleosts (Mecklenburg et. al 2002) while Apodichthys flavidus lacks a lateral line canal (Peterson et. al 1999). To test the rate of water flow through the canals, we placed a fish in a custom-built apparatus consisting of two orthogonal tubes: One with a steady, low volume flow of seawater to maintain constant water level/pressure and the other with its highest point $1 \mathrm{~cm}$ higher than the first tube and with an open end positioned over a calibrated digital balance (Fig. 2). Water flow was achieved with the use of a $5 \mathrm{~L}$ aspirator bottle filled with $12^{\circ} \mathrm{C}$ seawater placed on a shelf above the setup and attached with a barbed hose valve. The valve was opened just enough so that water would begin to overflow and drip from the first tube. Fish were anesthetized and placed in the tubes with about $1 / 2$ of their body in the open, empty tube and about $1 / 4$ of their body in the water filled tube. Water that moved across the fishes' bodies dripped onto the scale and the weight was recorded every 30 seconds for 15 minutes. The fish used in this experiment were: Xiphister mucosus $(\mathrm{N}=11)$, Anoplarchus purpurescens $(\mathrm{N}=6)$, and Apodicthys flavidus $(\mathrm{N}=5)$.

To test if it is the lateral line canal that facilitates water flow in Xiphister, using the same setup for testing overall water flow as previously described, anesthetized Xiphister $(\mathrm{N}=3)$ were placed in the tubes and water flow was recorded for three trials of three minutes each. In the first trial, all lateral line canals were unaltered. Prior to beginning the second three-minute trial, all canals of one side were blocked by injecting Vaseline ${ }^{\circledR}$ (about 1 $\mathrm{mg}$, depending on the size of the fish) into the canal directly through a canal pore using a 


\section{WATER TRANSPORT IN XIPHISTER MUCOSUS}

fine (34 $\mathrm{G}$ x 5/32) needle, creating a small, non-permanent but effective barrier. For the final three-minute trial, all canals (both sides of the fish) were blocked and flow rate was recorded.

\section{Evaporative Water Loss}

To test the potential benefit of a lateral line canal capable of transporting water we conducted two series of tests. First, fish Xiphister mucosus $(\mathrm{N}=10$, ranging in length from $157-322 \mathrm{~mm})$ and Anoplarchus purpurescens $(\mathrm{N}=10$, ranging in length from 132 $-150 \mathrm{~mm}$ ) were immobilized then tagged for identification using monofilament line and small colored beads. For the first experiment, all 20 fish were weighed and placed inside a $20 \mathrm{G}$ glass tank on platform raised above approximately $2.5 \mathrm{~cm}$ of $12^{\circ} \mathrm{C}$ saltwater. Five of each species were positioned entirely out of the water and five of each species were positioned with the most caudal quarter of their body submerged in water (Fig. 3, A \& B). The fish were allowed to dehydrate for one hour then weighed a second time, and placed back into a holding container filled with $12^{\circ} \mathrm{C}$ saltwater aerated with an aquarium bubbler. Fish were allowed to rehydrate for 30 minutes then were weighed and returned to the platform for one hour under the opposite condition (tail in/tail out) as their first hour, weighed and allowed to rehydrate for another 30 minutes then weighed a final time. Following a five-day recovery period, we performed a nearly identical experiment with the addition of all fish having the anterior trunk of their bodies wrapped in nylon cloth to simulate the natural condition of skin contact with sand, rocks, algae or other Stichaeids experienced under more natural conditions (Fig. 3, C \& D). Prior to wrapping each fish 


\section{WATER TRANSPORT IN XIPHISTER MUCOSUS}

the nylon was wetted, wrung of excess moisture and weighed so as not to influence the amount of water on the fish.

Utilization of nylon wrapping was done in accordance with our experience handling Xiphister, during which we observed their skin would become increasingly tacky to the touch with longer direct exposure to ambient air, but would remoisten upon our manual contact with the lateral line canal.

Post experimentation, known measurements were used to infer the surface area of each fish by assuming the body shape to be roughly that of a cylinder. This was done to standardize the data into grams of water lost per square millimeter of surface area per hour $\left(\mathrm{g} \mathrm{mm}^{2-1} \mathrm{~h}^{-1}\right)$.

\section{Data}

Statistical data was first organized in Microsoft Excel 2008 then analyzed in RStudio using the Mann-Whitney-Wilcoxon test because we are comparing two independent groups and cannot assume a normal distribution of evaporative water loss occurring between the two species under the differing conditions. Combinations of experimental groups occurring under the differing test conditions were compared to determine significance.

\subsection{Results}

\section{Dye Transport}

Dye applied to the skin of Xiphister rapidly moved through the branched canal system. In less than 15 seconds, multiple drops of dye were observed to perfuse the entire length of 


\section{WATER TRANSPORT IN XIPHISTER MUCOSUS}

the canal. Dye movement can be seen in Figure 4. When this same test was performed on a goldfish (Carassius auratus) no dye movement was observed.

\section{Flow Rate}

The trunk lateral line canals of $X$. mucosus can readily transport water with a mean rate of $0.35 \mathrm{ml} / \mathrm{min}$. This occurs with either the help of gravity or when adhesive forces from contact with surrounding surfaces induce capillary action. There was no water movement observed in either Anoplarchus or Apodichthys (Fig. 5).

Blocking the lateral line canal of $X$. mucosus stopped the water flow through the canal. With half of the lateral line canals (all canals on one side) blocked, water flow was reduced by half. When all canals on both sides were blocked, water movement ceased entirely (Fig. 6).

\section{Evaporative Water Loss}

Water loss was measured in fish under four conditions (Fig. 7). In the first condition, when fish were kept in air and allowed to dehydrate both Xiphister and Anoplarchus lose water at approximately the same rate, between 3 and $4 \mathrm{~g} \mathrm{~mm}^{2-1} \mathrm{~h}^{-1}$. The second condition was identical to the first, except that the fish's tail was kept in water. Anoplarchus does not show an improvement in water loss but Xiphister has significantly less loss compared with the tail in air situation. In the third condition, fish were wrapped to simulate their natural hiding mode of nestling in algae coated rock crevices, and they did not have their tail in water. Anoplarchus did not improve its water loss when wrapped, but Xiphister showed the same improvement as when its tail was in water but not wrapped. That is, approximately $2.5 \mathrm{~g} \mathrm{~mm}^{2-1} \mathrm{~h}^{-1}$ loss or an improvement of $0.5 \mathrm{~g} \mathrm{~mm}^{2-1} \mathrm{~h}^{-1}$. Finally, in the 


\section{WATER TRANSPORT IN XIPHISTER MUCOSUS}

fourth test condition fish were allowed both potential aids to compensate for evaporative water loss: they were wrapped and their tails were in water. Anoplarchus remained at its control (condition 1) water loss level but Xiphister showed an additive effect, reducing its water loss to $1 \mathrm{~g} \mathrm{~mm} \mathrm{~h}$. Figure 8 shows that when the two species are compared under the fourth test condition, Xiphister is approximately three times better at compensating for water loss $(\mathrm{P}<0.001)$. Overall, comparing the mean loss of all conditions for the two species shows Xiphister to be significantly $(\mathrm{P}<0.001)$ better than Anoplarchus at minimizing water loss (Fig. 9).

\subsection{Discussion}

The trunk lateral line canals of $X$. mucosus can transport water and this slows evaporative water loss. This occurs most readily with either the help of gravity or when adhesive forces from contact with surrounding surfaces (such as rock, sand, algae, or other fishes) initiate capillary action. By comparing wrapped Xiphister to unwrapped Xiphister, both groups without immersed tails, it is clear that wrapping slows water loss. This, in conjunction with the significant difference between unwrapped Xiphister with immersed tails and unwrapped Xiphister with tail in water suggests that while wrapping slows the evaporation rate, allowing the tail (and lateral line canal), access to water also plays a significant role in slowing evaporative water loss. Owing to the relatively impermeable skin of Xiphister, this additive effect supports the hypothesis that it may be the lateral line canal that is slowing water loss as opposed to the skin and that the adhesive forces of the nylon-to-skin contact contribute to driving water transport within the canals. This could be an extremely beneficial trait in the intertidal where long periods of exposure from 


\section{WATER TRANSPORT IN XIPHISTER MUCOSUS}

water during low tides might necessitate some method, either morphological or behavioral, to avoid desiccation. Daxboeck \& Heming (1982) reported that Xiphister, while normally remaining upright during times of emersion, would on occasion roll onto their sides into what little water was left on their testing surface. According to our study, this water would not only wet the skin but would also be pulled into the lateral line canals, which may be acting as a reservoir in order to help maintain skin moisture. It is likely that in conjunction with desiccation avoidance the lateral line canal system of Xiphister is used to move water across the skin to maintain the level of moisture necessary for cutaneous respiration. Since Xiphister potentially spend half of their lives out of water, the ability to efficiently diffuse $\mathrm{O}_{2}$ and $\mathrm{CO}_{2}$ across the skin's surface is vital. We began preliminary experiments regarding cutaneous respiration (Chapter 3), but have yet to study this particular topic. So for now we will suggest that the complex system of branching canals of $X$. mucosus is predominantly for desiccation avoidance and rehydration assistance, though the mechanics behind this process remain unknown. This trait appears to allow $X$. mucosus to be able to withstand evaporative water loss, perhaps due to its ability to quickly rehydrate as found by Horn \& Riegle (1981) who found $X$. mисоsus gained water more quickly (sometimes even exceeding its beginning weight) when compared to A. purpurescens. However, in the same study, A. purpurescens was found to lose water at a slower rate than $X$. mucosus, which was incongruent with our findings.

This brings up the question of metabolic activity. If $X$. mucosus is taking on seawater, how are they dealing with the influx of ions? Marine teleosts drink seawater to offset the 


\section{WATER TRANSPORT IN XIPHISTER MUCOSUS}

loss of ions and osmotic pressure to their saline surroundings. Water and ions are absorbed through the epithelial lining of gut while excess ions are removed via mitochondria-rich active transport cells in the gills and skin and also in the form of concentrated urine (Hill, 2004). Evans (1967) showed that Xiphister skin is fairly impermeable to water or sodium and chloride ions. Compared to other teleosts, he found that Xiphister had a much lower rate $(25-50 \%)$ of flux of sodium and chlorides in both normal seawater salinity $(100 \%)$ and $10 \%$ salinity. While there have not been tests to determine if emersion leads to altered permeability, we will adhere to the notion that Xiphister skin is in general relatively impermeable to water leading us to speculate that during our experiments they could have been drinking water from the skin, taking it in through their gills or possibly even using incoming moisture to add to their slime coat. This begs the question of whether or not the conditions under which our Xiphister gained water also leads to an increase in metabolic rate due to the possibly need for ion excretion, which can be energetically costly as chloride cells in the skin use active transport to expel ions. We have already done some preliminary research, and suggest that this is an important area for future research. What if under terrestrial conditions the skin is in fact more permeable than the hyposaline conditions under which Evans (1967) tested? If so, another interesting dimension to explore would be the change in ion balance that might occur if the fish rehydrates via the skin or by drinking the water moved through the lateral line canals. Further research should also include histological investigations into the ion-exchange mechanisms employed by $X$. mucosus during terrestrial emergence. 


\section{WATER TRANSPORT IN XIPHISTER MUCOSUS}

Curiously, there was always a temporal difference between the first and second evaporative water loss treatments - the second treatment always lost more water regardless of condition. While our results are clear, it may have been beneficial if we only performed a single, albeit longer, treatment per experimentation day, which would better recreate a more natural low-tide scenario. We may also have produced interesting results by running similar experiments, but testing plasma osmolarity instead of relying on weight.

Horn and Riegle (1981) recorded that the distribution pattern in the intertidal zone showed X. mucosus to be found at greatest abundance +0.2 to $+0.4 \mathrm{~m}$ relative to the mean lower low water level, with a maximum vertical height of $+0.8 \mathrm{~m}$., exposing it to a more terrestrial existence than $X$. atropurpureus that was found in greatest abundance at 0.0 to $-0.2 \mathrm{~m}$. This might explain the discrepancy between the sensory abilities of the lateral line canal between the congeners - where Bleckmann \& Münz (1990) found X. atropurpureus to have them while Kaldenbach (dissertation) found X. mucosus to not. Future iterations of our water transport test would benefit by using a greater number of species for comparison; the Anoplarchus lateral line has been described as rudimentary (Pepar, 1965, Peden 1966) and was not easily discernible, which may have confounded our results. This study would gain rigor from comparing a greater range of canal morphology variation. In particular, Cebidichthys violaceus and Phytichthys chirus are other intertidal fish we would have liked to compare against $X$. mucosus, however we were not granted the permit to collect either. C. violaceus has a more prominent lateral line canal than Anoplarchus. P. chirus was formerly placed in the genus Xiphister and 


\section{WATER TRANSPORT IN XIPHISTER MUCOSUS}

like $X$. mucosus and $X$. atropurpureus, it has a multiple, branched canal system and is found in similar habitats, although little is known about the $P$. chirus mechanosensory lateral line canal. While we were permitted to collect $X$. atropurpureus and Apodichthys flavidus, we were unable to collect enough specimens to include in this study. We were also unable to collect many large Xiphister specimens. Including larger fish would have allowed us to block the canals during the evaporative water loss experiments as we did for the water transport experiment.

Our data show that the $X$. mucosus lateral line canal is effective at slowing evaporative water loss, and although we have not tested many other species, we posit that this is a unique adaptation not found in other intertidal fish. 


\section{WATER TRANSPORT IN XIPHISTER MUCOSUS}

\section{Preliminary Observations of the Metabolic Consequences of Water Loss in Xiphister mucosus (Girard 1858)}

\subsection{Introduction}

In our previous set of experiments, we examined the lateral line trunk canal of $X$. mucosus and determined that its complex morphology provides a unique ability to transport water, potentially affording this species some benefit during low-tide intervals when it and other members of the Stichaeidae family remain above the waterline. To follow up on that work, we looked into the metabolic activity of $X$. mucosus during periods of air exposure.

Cellular membranes must be wet in order to function and allow gas diffusion. While Xiphister secretes a protective layer of mucus, it is possible that significant levels of dehydration may require a trait, such as a lateral line canal able to transport water across the body, to maintain the moisture necessary for the skin to function as a respiratory surface. Before this can be tested, however, we needed to confirm the long held supposition that Xiphister rely on cutaneous respiration during periods of emersion. Daxboek and Hemming (1982) are most often cited when discussing Xiphister cutaneous respiration in air. However, while their suggestion is more than reasonable - Daxboek and Hemming describe the easily observed dilation of blood vessels at the skin's surface - we were unable to find previous studies citing empirical evidence supporting this assumption. We hypothesize that by impeding a portion of the body's diffusion surface oxygen consumption should drop, allowing us to observe its importance as functional respiratory surface. Observation of regular opercular movement while our specimens 


\section{WATER TRANSPORT IN XIPHISTER MUCOSUS}

were emersed lead us to hypothesize $X$. mucosus' aerial respiration methods may involve more than only cutaneous respiration. After determining cutaneous respiration is in fact a major component of aerial respiration, we compared the metabolic activity of the body against that of the head to determine the importance of cutaneous respiration against buccal pumping and air swallowing as primary methods of aerial respiration. Martin and Horn (2006) discuss $X$. atropurpureus having cartilaginous rods that may support their gill lamellae to aid in aerial respiration, so it could be assumed that $X$. mucosus may have this trait as well. Our findings support the long assumed notion that gas diffusion across the skin's surface is more important than other internal surfaces.

We also wanted to examine lateral line canal structure as a possible respiratory surface. To determine if the elaborate structure provides a greater surface area for $\mathrm{O}_{2} / \mathrm{CO}_{2}$ diffusion we compared the metabolic activity of $X$. mucosus with the lateral line trunk canal either unaltered or completely blocked. The surface area of lateral line canal appears to nearly double the overall skin surface area of $X$. mucosus, as such, we hypothesized that when exposed to air, X. mucosus with a blocked lateral line canal would exhibit a decline in metabolic rate as compared to one with an unaltered lateral line canal. This was not the case - inconclusive evidence leaves us unable to confirm that the surface area of the lateral line contributes to metabolic activity.

\subsection{Methods}

All metabolic tests were preformed in a sealed acrylic test chamber designed specifically for this experiment (Figs. $10 \& 11$ ), and were run at constant temperature $\left(12^{\circ} \mathrm{C}\right)$ with a 


\section{WATER TRANSPORT IN XIPHISTER MUCOSUS}

starting oxygen partial pressure of $20.5 \%$. Fish were denied food for 24 hours prior to experimentation, then were transferred to a container with 1\% MS 222 (tricaine methanesulfonate/3-aminobenzoic acid ethyl ester methanesulfonate; Western Chemical, Inc.) in seawater for initial sedation. Once unresponsive they were immobilized with an injection of pancuronium bromide ( $0.25 \mu \mathrm{g} / \mathrm{g}$ bodyweight; Hospira, Inc.). Following experiments, fish were placed in partitioned enclosures within their "home" tank for monitoring recovery. The testing chamber incorporated an oxygen probe [Vernier, O2BTA] with a measurement range of $0-27 \%(0-270 \mathrm{ppt})$, an accuracy of $+/-1 \%$ volume $\mathrm{O}_{2}$ at standard pressure $(760 \mathrm{~mm} \mathrm{Hg})$, and a resolution of $0.01 \%$. To avoid pressure effects on the $\mathrm{O}_{2}$ sensor when closing the chamber, one end of the chamber was sealed off with a flexible gasket (we used the thumb of a latex glove). Prior to running any experiments with fish, we ran a series of tests to see if it would be necessary to account for any metabolic activity of bacteria living on the fishes' skin. Un-anesthetized individuals were placed in the chamber and allowed to move about, coating the inside of the chamber with mucous and any bacteria present on the skin. The fish were then removed and the sealed chamber was sampled with the $\mathrm{O}_{2}$ sensor. After four tests run for three hours each, we observed no measurable metabolic activity by bacterium normally present on the skin of the fish. Fish were fasted for 32 hours prior to testing to ensure we were testing them at their standard metabolic rate. Between each test involving a Xiphister the chamber was left open for no less than 15 minutes to remove excess $\mathrm{CO}_{2}$ and restore the inner chamber partial pressure of $\mathrm{O}_{2}(20.5 \%)$. 


\section{WATER TRANSPORT IN XIPHISTER MUCOSUS}

1. In order to determine that Xiphister relies on cutaneous respiration, we tested the metabolic rate of one Xiphister under two conditions. First the fish was placed on a raised mesh screen, which allowed for air movement around the body. Second, the fish was placed lying in the bottom of out metabolic chamber - its concave surface cradling the fish and effectively blocking half of the body from the air inside the chamber (Fig. 10). Each test session (three of each condition for a total of six sessions) lasted for 30 minutes and $\mathrm{O}_{2}$ measurements were taken every ten seconds. ANCOVA was used to test whether the slope variables were significantly different.

2. Next, we tested Xiphister in a chamber partitioned just behind the operculum with an oxygen probe on either side. The partition gasket was created using the thumb of a latex glove (washed to remove any particulate glove coating), with the wider end stretched over one half of the chamber leaving the more narrow end for the fish. Specimens $(\mathrm{N}=7)$ were tested on a raised platform to allow the full cutaneous surface to be compared against the potential internal gas exchange (Fig. 11). To compare the two chambers, we found the slope of the regression line, giving the decrease of $\mathrm{O}_{2}$ concentration in the chambers per time, quantifying the oxygen consumption. To correct for different chamber sizes, we multiplied each respective chamber length by the $\mathrm{O}_{2}$ consumption rate. We then determined the ratio of corrected $\mathrm{O}_{2}$ consumption.

3. Finally, we investigated if Xiphister is able to utilize the excess surface area of the trunk canal system as a potential diffusion surface. Using a fine $(34 \mathrm{G}$ x 5/32) needle and Vaseline ${ }^{\circledR}$, we filled the canals blocking the inner surface entirely. This procedure 


\section{WATER TRANSPORT IN XIPHISTER MUCOSUS}

appeared to have no lasting effect on the fish and after 1-2 weeks it was noted that a once blocked specimen was no longer blocked. We ran this experiment with the fish lying on the bottom of the test chamber. Blocked $(\mathrm{N}=3)$, unblocked $(\mathrm{N}=3)$.

\subsection{Results}

1. When the fish was placed on the floor of the cylindrical testing chamber, effectively blocking half of skin to air exposure, cutaneous respiration could not occur at that surface leading to a near halving of the oxygen consumption rate as compared to Xiphister raised on a mesh platform (Fig. 12). When lying flat in the chamber the average slope of rate of consumption was -1.9 , when raised average slope of rate of consumption was -3.5 . This significant difference (ANCOVA $\mathrm{P}<0.001$ ) in oxygen consumption suggests that Xiphister relies heavily on its skin as an aerial respiratory surface.

2. With the body partitioned into separate chambers and the data normalized to rate of consumption per $\mathrm{mm}^{2}$ of the skin's surface area, the trunk and head showed an equal rate of oxygen consumption. However, when the different sized portions of the body in the two chambers are factored in, our measurements reveal that the Xiphister consumed on average $(\mathrm{N}=9), 6$ times more oxygen with their trunk than with their head and inner epithelial surfaces suggesting Xiphister rely more extensively on cutaneous respiration than buccal pumping or air swallowing (Figs. $13 \& 14$ ).

3. There was no significant difference $(t$ test $\mathrm{P}>0.5)$ between metabolic rates of fish that had their entire canal blocked vs. those fish that had the full use of the canal surface for respiration (Fig. 15). 


\section{WATER TRANSPORT IN XIPHISTER MUCOSUS}

\subsection{Discussion}

The non-significant differences that we reported in the third tests could be due to a number of factors. It could certainly be that there in no difference in metabolic rate under this particular set of conditions. Randal (1970) says that fish blood has a high oxygen affinity and can be $95 \%$ saturated, even at very low oxygen partial pressures; adding to that, gas diffusion through air is far more efficient due to air having a higher partial pressure of oxygen than water. Daxboeck and Hemming show that the $X$. mucosus congener, $X$. atropurpureus in air is able to surpass their oxygen uptake recorded in water. It is possible that in our study the increase in diffusion efficiency combined with high saturation masked any observable differences. Another possibility is that our experiments were simply run at too short of a duration to demonstrate any differences - it might be necessary for the skin to become more dry (or the fish to become dehydrated) before any physiological response that may lead to depressed metabolism begin. The lateral line canal surface might still have the potential to be used as a surface for gas exchange - it could be that the skin's surface was sufficient to provide needed oxygen during that basal level of activity, and impeding a portion of the diffusion surface caused no change in consumption rate. A difference might show up with increased levels of activity but it was not possible to test this with our experimental design and it is natural for Xiphister to remain inactive during low tide. It could also be possible that the lateral line canal is in no way associated with respiration. In its natural habitat, upon emergence Xiphister generally is able to wedge its long, narrow body into deep interstices between and under rocks where the humidity may be sufficient to prevent desiccation and obviate the need 


\section{WATER TRANSPORT IN XIPHISTER MUCOSUS}

for any special adaptive trait yet in such an environment, it is likely the canal would remain filled with water or mucus.

It has been shown in many cases that there are numerous adaptations and variations of aerial respiration in amphibious fish, but it has only been studied in some of the many different species (Bridges, 1993; Graham, 1997). Feder and Burggren (1985) reviewed other respiration studies that involved partitioning the head and body of fishes and the findings suggest that while all air-breathing fishes use the skin as an accessory respiration organ, the epithelial cells of the gills or buccal cavity are often used as a primary diffusion site. However, in our tests significant differences were observed when fish were flat or raised and when the fish's body was partitioned, both supporting the decades long assumption that cutaneous respiration is the primary mode of aerial respiration in Xiphister.

As an intertidal and estuary dwelling fish, $X$. mucosus is subject to not only periods of emersion from water, but also exposure to euryhaline conditions. When experiencing low-saline conditions, $X$. mucosus has been shown to quickly depress metabolic rate and fall into a light torpor from which they rapidly recover upon exposure to normal levels of seawater salinity (Haynes, 2009). It's possible that Xiphister relies on a similar tactic when, during aerial respiration, dehydration might disrupt cutaneous respiration. In future studies, we would like to compare metabolic rate and cardiac response of Xiphister under longer periods of aerial respiration under both dehydrated conditions and moist conditions as well as against immersed respiration. 


\section{WATER TRANSPORT IN XIPHISTER MUCOSUS}

\section{Figures}

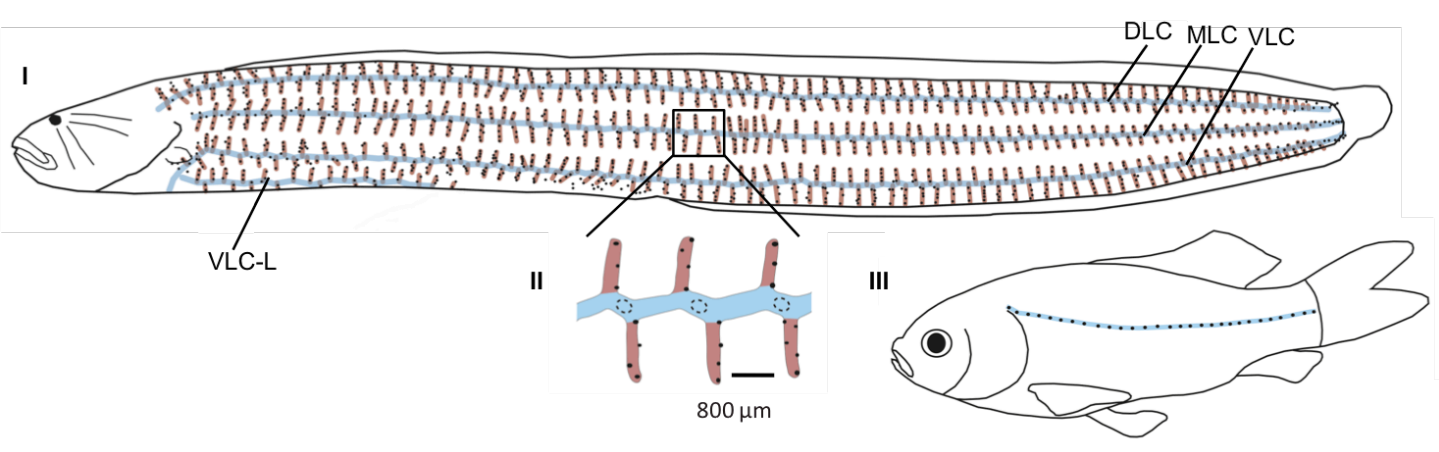

Figure 1 Diagram of Xiphister lateral line canal. The trunk lateral line canal system of Xiphister mucosus (I \& II) as compared to the most commonly observed lateral line canal morphology (III). Credit: Felix Kaldenbach 


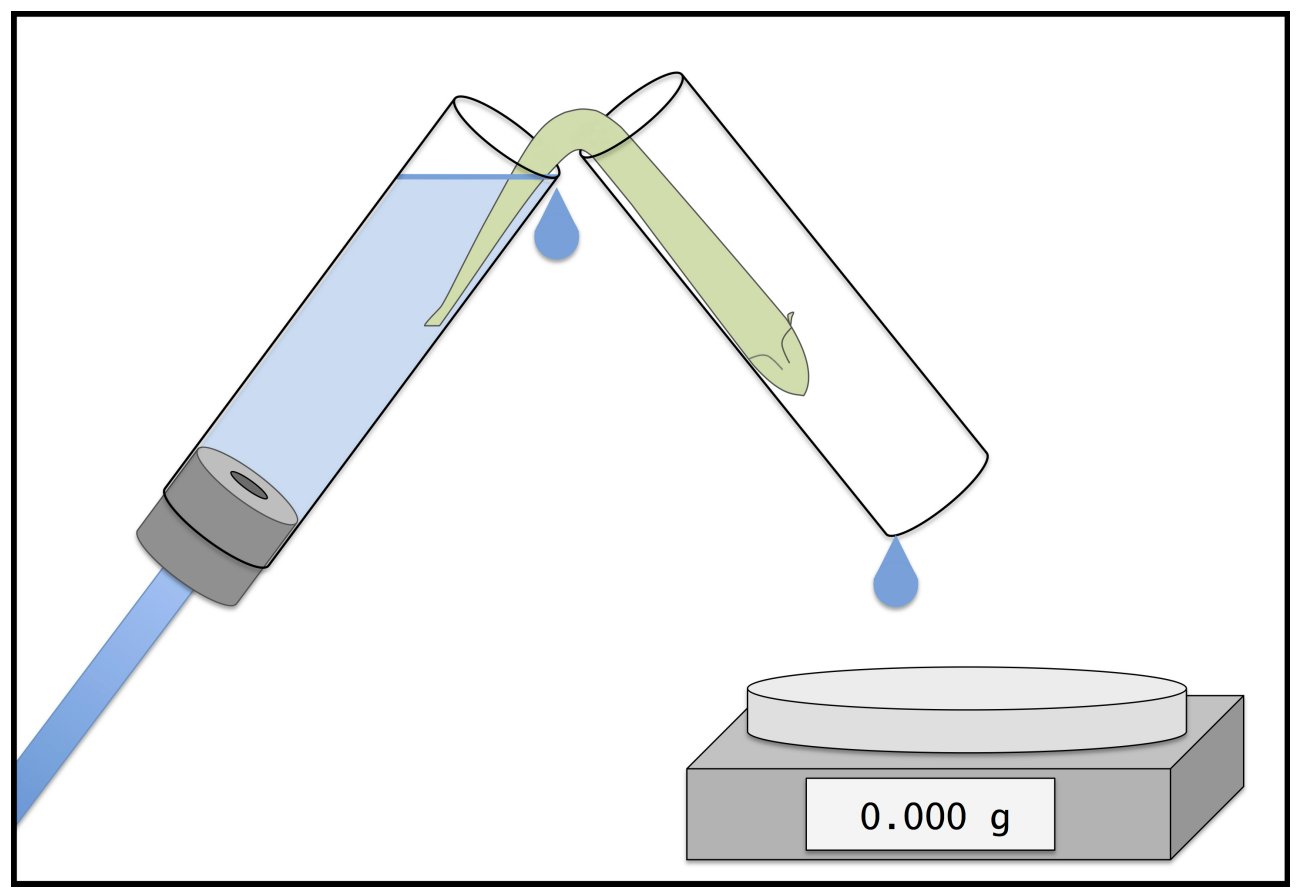

Figure 2 Canal water transport setup. Water transport experiment setup constructed with two orthogonal tubes: one with a steady, low volume flow of water to maintain constant water level/pressure to ensure equal flow rates and the other with its highest point $1 \mathrm{~cm}$ higher than the other tube and an open end over a scale to measure transported water weight. Fish were positioned with $\approx 1 / 4$ of their body submerged in the water filled tube. 


\section{WATER TRANSPORT IN XIPHISTER MUCOSUS}
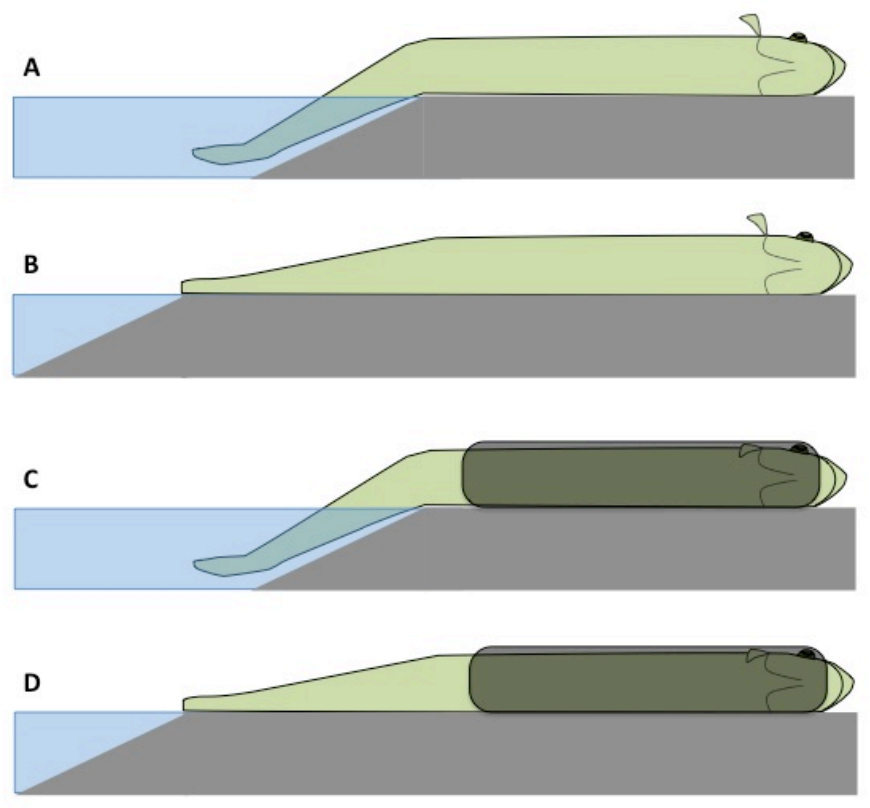

Figure 3 Evaporative water loss setup. Xiphister and Anoplarchus positioned on a partially submerged platform under one of four conditions: A. without nylon wrap with tail in the water, B. without nylon wrap with tail out of the water, C. with nylon wrap and tail in the water, D. with nylon wrap and tail out of the water.

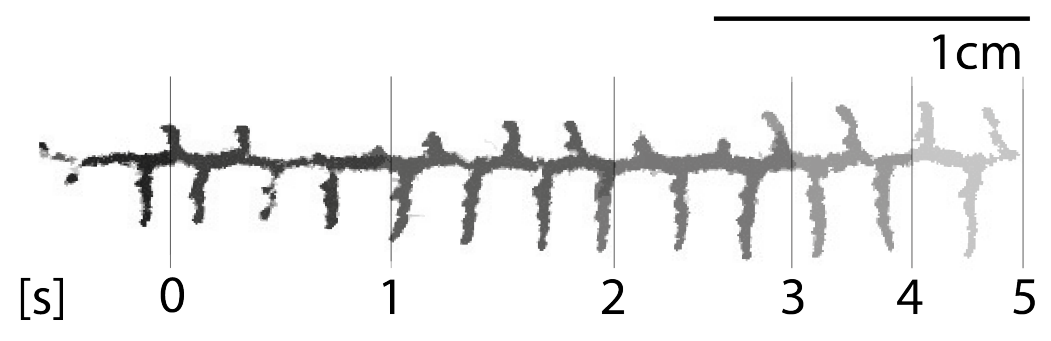

Figure 4 Dye transport results. Application of dye to the skin of Xiphister results in rapid transport through the canal system. This diagram shows the extent of dye migration over a short time in one test with one fish. By $5 \mathrm{~s}$ a single dye was transported over $3 \mathrm{~cm}$. 


\section{WATER TRANSPORT IN XIPHISTER MUCOSUS}

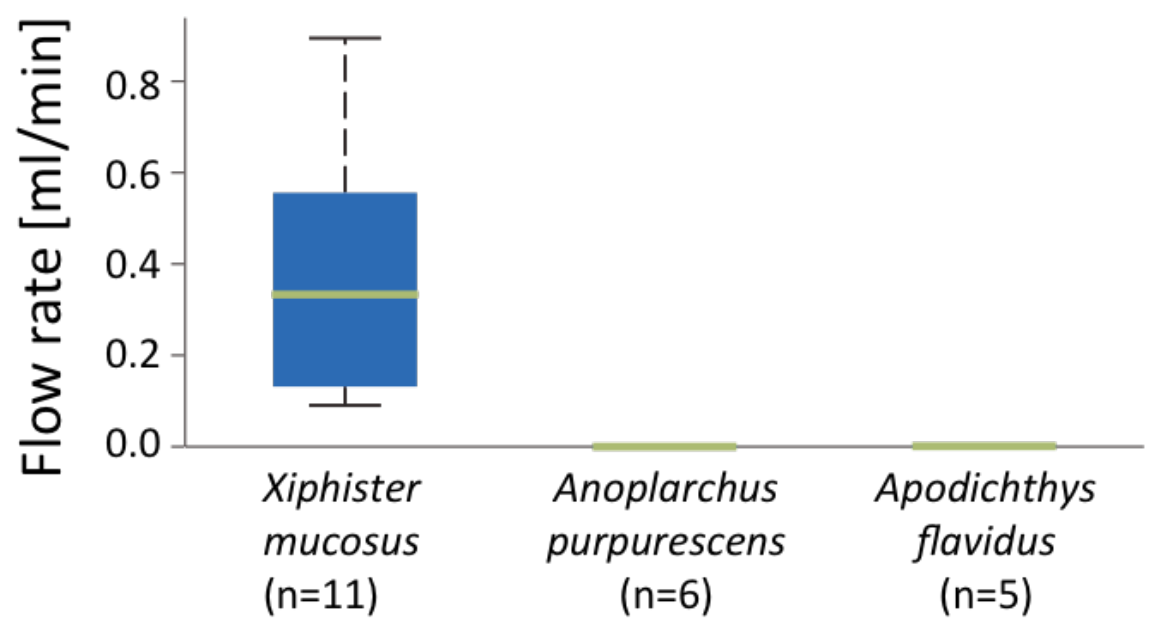

Figure 5 Water flow rates in the lateral line canals of three fishes. The flow rate of water through the lateral line canals of three similar species in the suborder Zoarcoidei: Xiphister mucosus, Anoplarchus purpurescens, and Apodichthys flavidus. Xiphister mucosus was the only species to show any water movement with a flow rate mean of $0.35 \mathrm{ml} / \mathrm{min}$ over the course of 15 minutes.

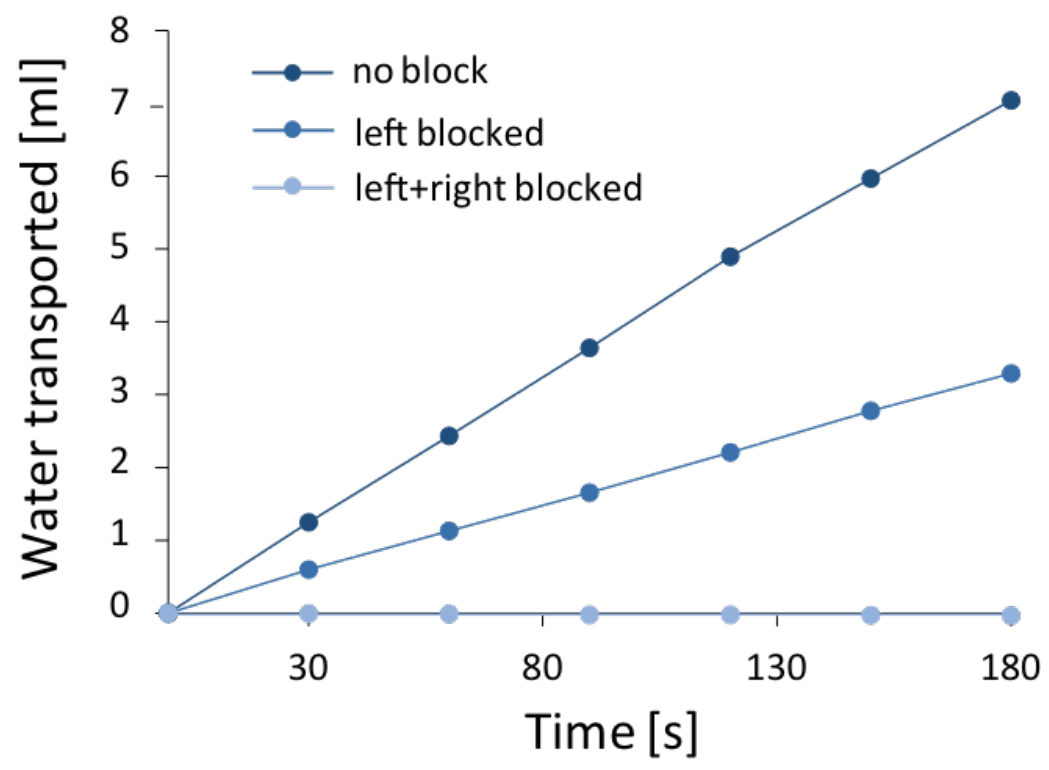

Figure 6 Water flow rates in the lateral line canal of Xiphister mucosus. Upon blocking the canals with Vaseline the rate declined with each line blocked. Blocking all canals on one side lead to a nearly half reduction in flow rate while blocking all canals on both sides stopped all water flow. $\mathbf{N}=1$ 


\section{WATER TRANSPORT IN XIPHISTER MUCOSUS}

A

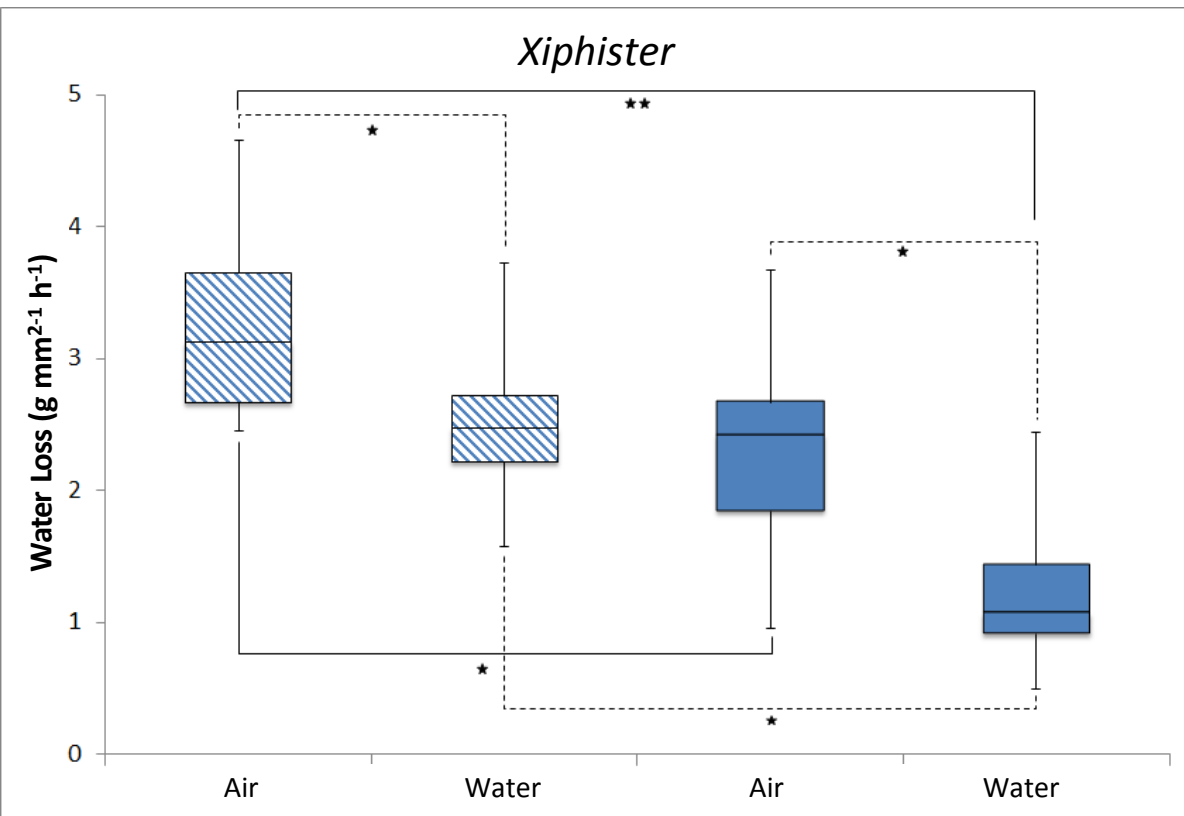

B

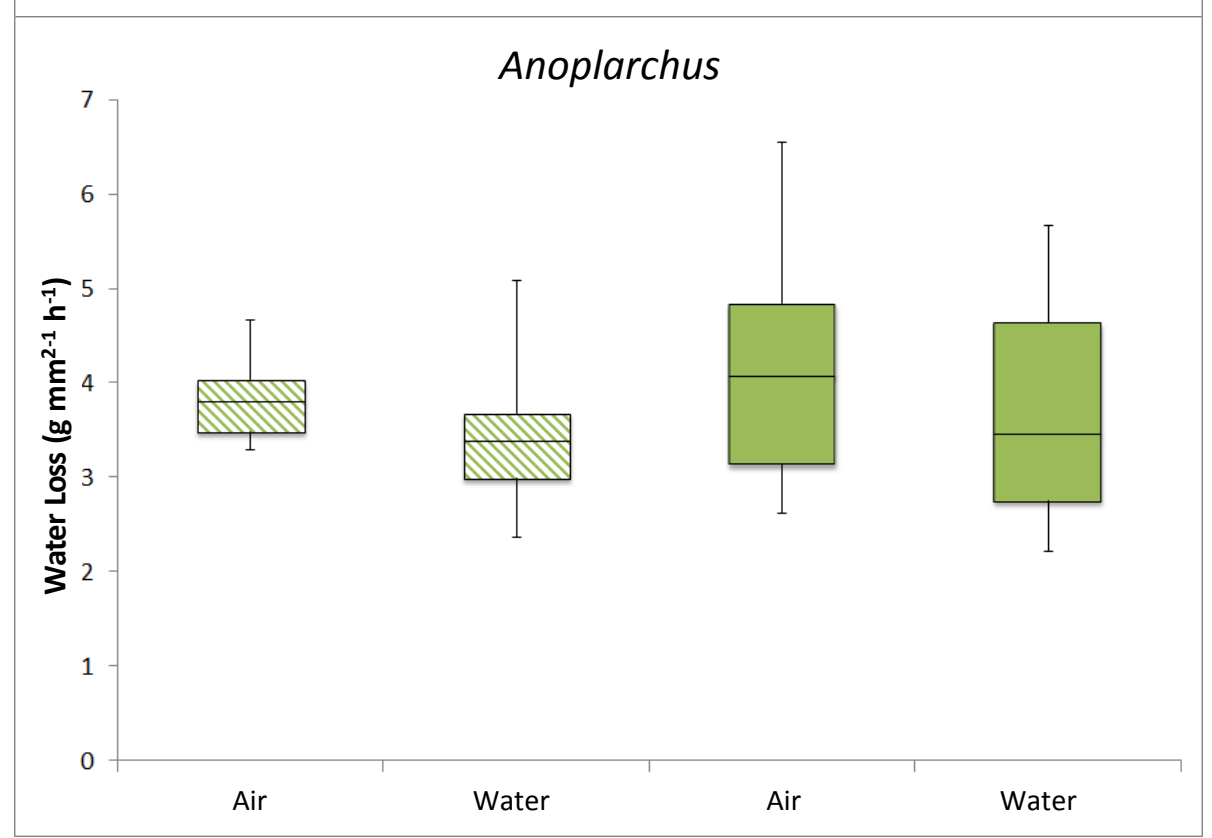

Figure 7 Evaporative water loss results all fish, all conditions. Box plots of evaporative water loss data for Xiphister mucosus (A) and Anoplarchus purpurescens (B). Lined boxes denote the condition of fish not being wrapped while solid boxed denote the condition of fish being wrapped in nylon. Under all sets of conditions Xiphister lost less water per unit of surface area than Anoplarchus. The overall mean loss for Xiphister was $2.3 \mathrm{~g} \mathrm{~mm}^{2-1} \mathrm{~h}^{-1}$, while the overall mean loss for Anoplarchus was $3.8 \mathrm{~g} \mathrm{~mm}^{2-1} \mathrm{~h}^{-1}$. No difference was observed between any of the different Anoplarchus groups. Nearly all Xiphister groups showed a significant difference in water loss when compared to one another as noted by $t$ 's. This suggests that both being wrapped and having the tail in water are additive conditions. $\vec{\psi}=$ significance of $P<0.05 ; \vec{\psi} \forall=$ significance of $P<0.001 ; N=10$ of each species under each condition. 


\section{WATER TRANSPORT IN XIPHISTER MUCOSUS}

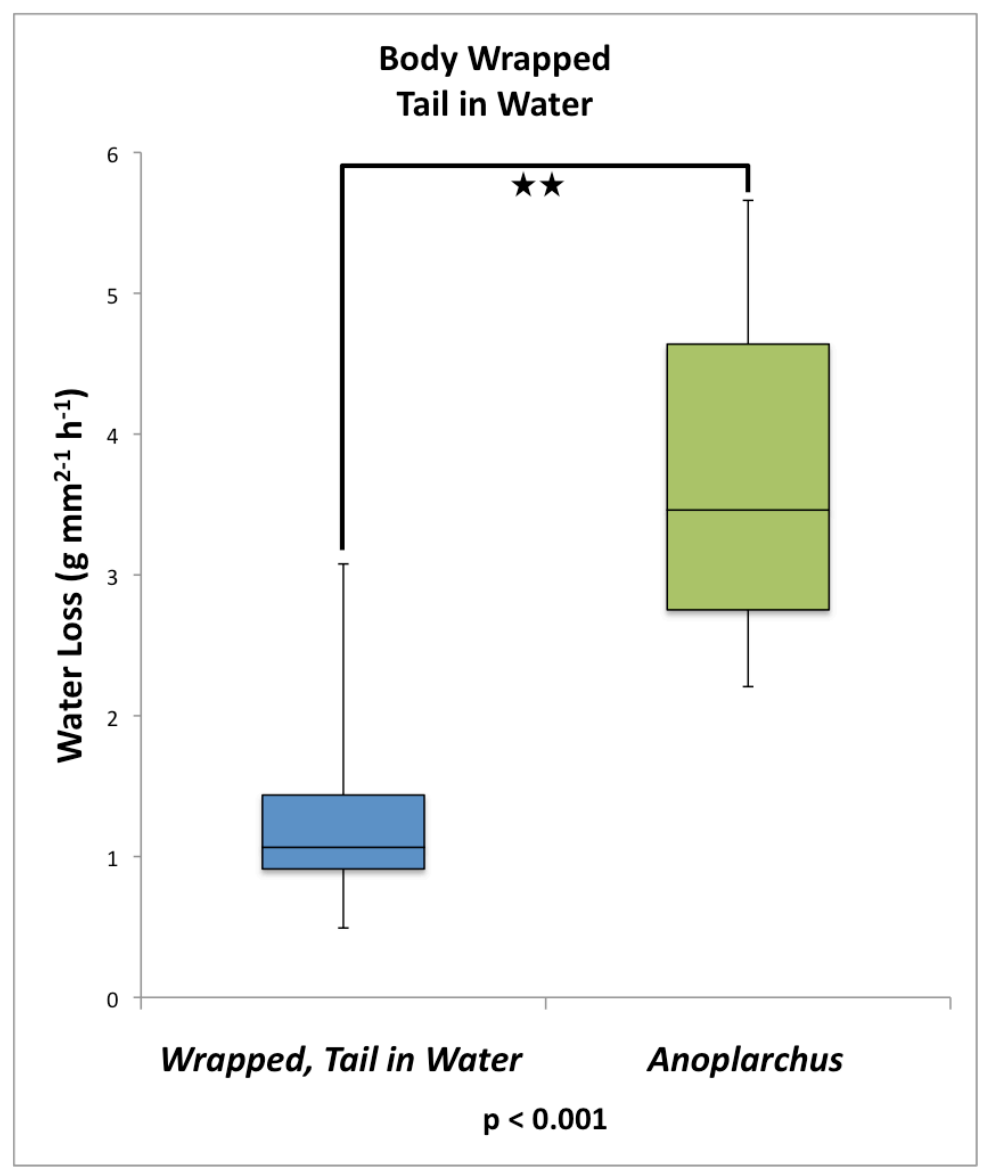

Figure 8 Xiphister vs. Anoplarchus, wrapped with tail immersed. Xiphister (Xm ww) loses water per unit of surface are significantly slower than Anoplarchus (Ap ww) when both species are tested under the same condition of being wrapped and having their tail in water. $t \leqslant P<0.001$ 


\section{WATER TRANSPORT IN XIPHISTER MUCOSUS}

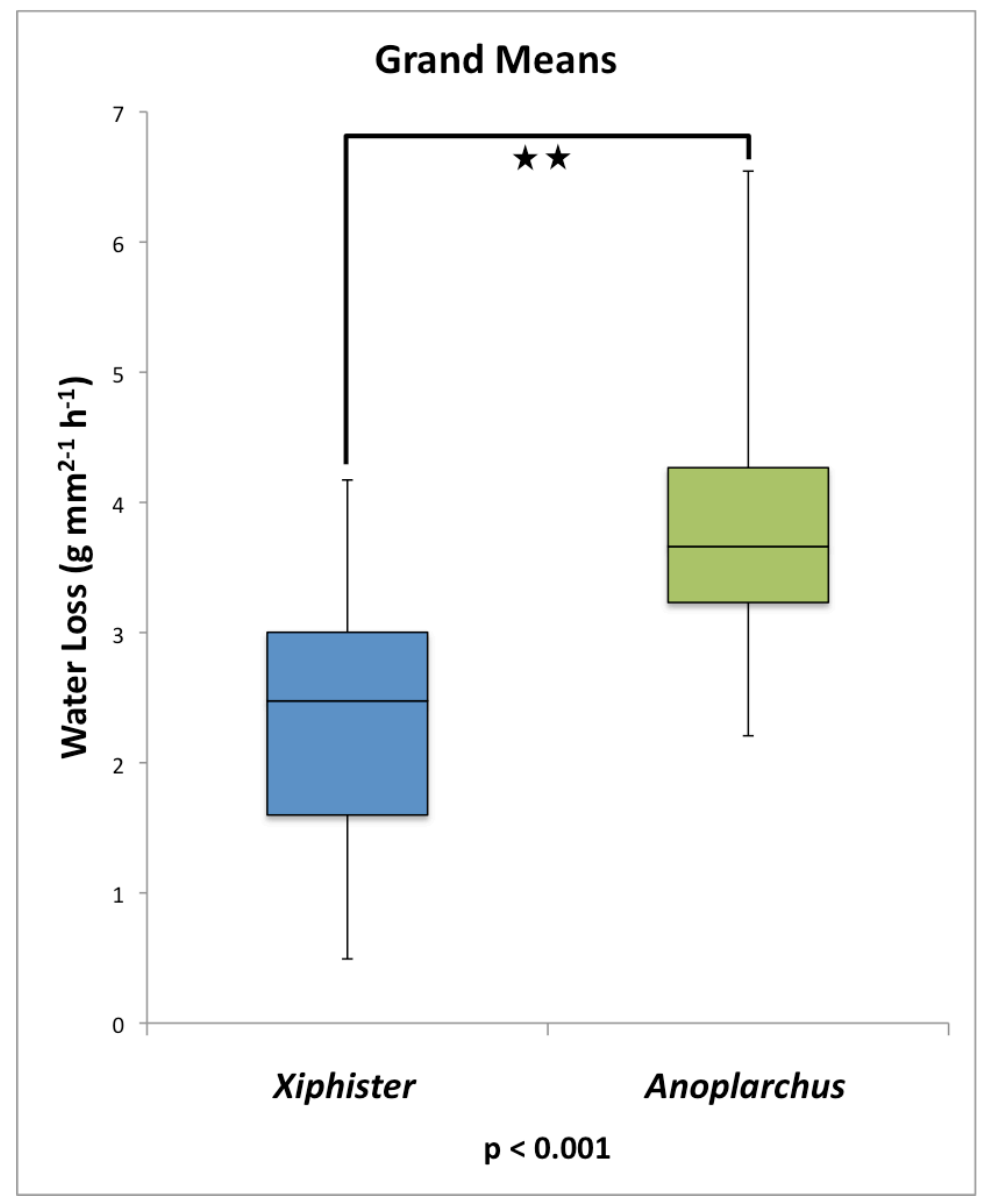

Figure 9 Evaporative water loss results: all means. The grand means of Xiphister and Anoplarchus under all sets of conditions (wrapped/not wrapped and tail in water/tail out of water). Xiphister (Xm all) lost less water per unit of surface area than Anoplarchus (Ap all). N = 10 of each species under each

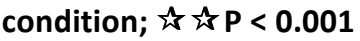




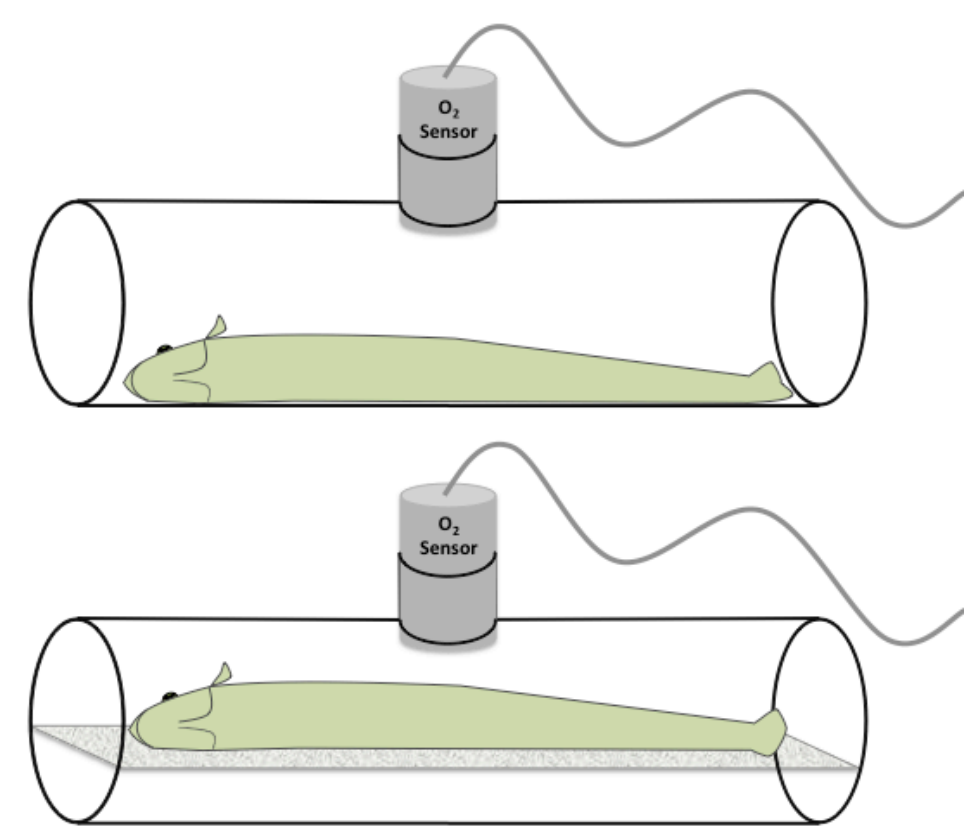

Figure 10 Xiphister in a metabolic chamber, either flat with half of their skin's surface area flush against the acrylic tubing or on a suspended mesh surface allowing for air movement across the entire body.

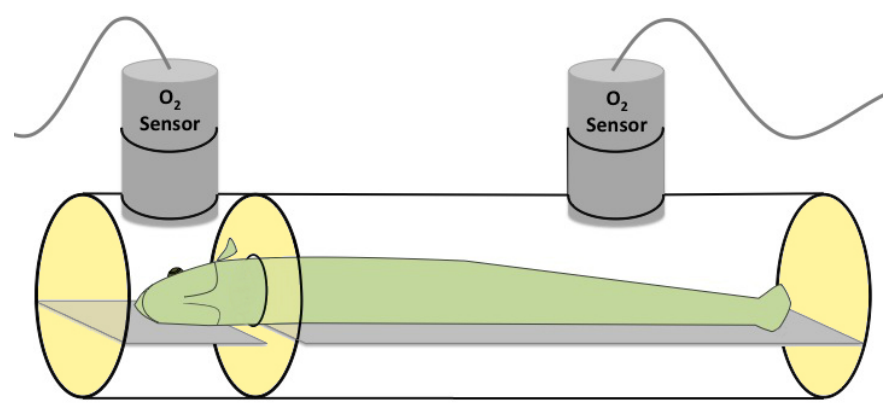

Figure 11 Xiphister in a partitioned metabolic testing chamber. To test cutaneous respiration of the body against any potential out of water gill function or use of epithelial tissue of the mouth or digestive tract via buccal pumping as a surface for gas exchange, each Xiphister tested was placed in a partitioned and sealed metabolic chamber with the majority of the body on one side and the gills and mouth on the other. Oxygen levels were collected every ten seconds for thirty minutes. $\mathbf{N}=\mathbf{9}$ 


\section{WATER TRANSPORT IN XIPHISTER MUCOSUS}

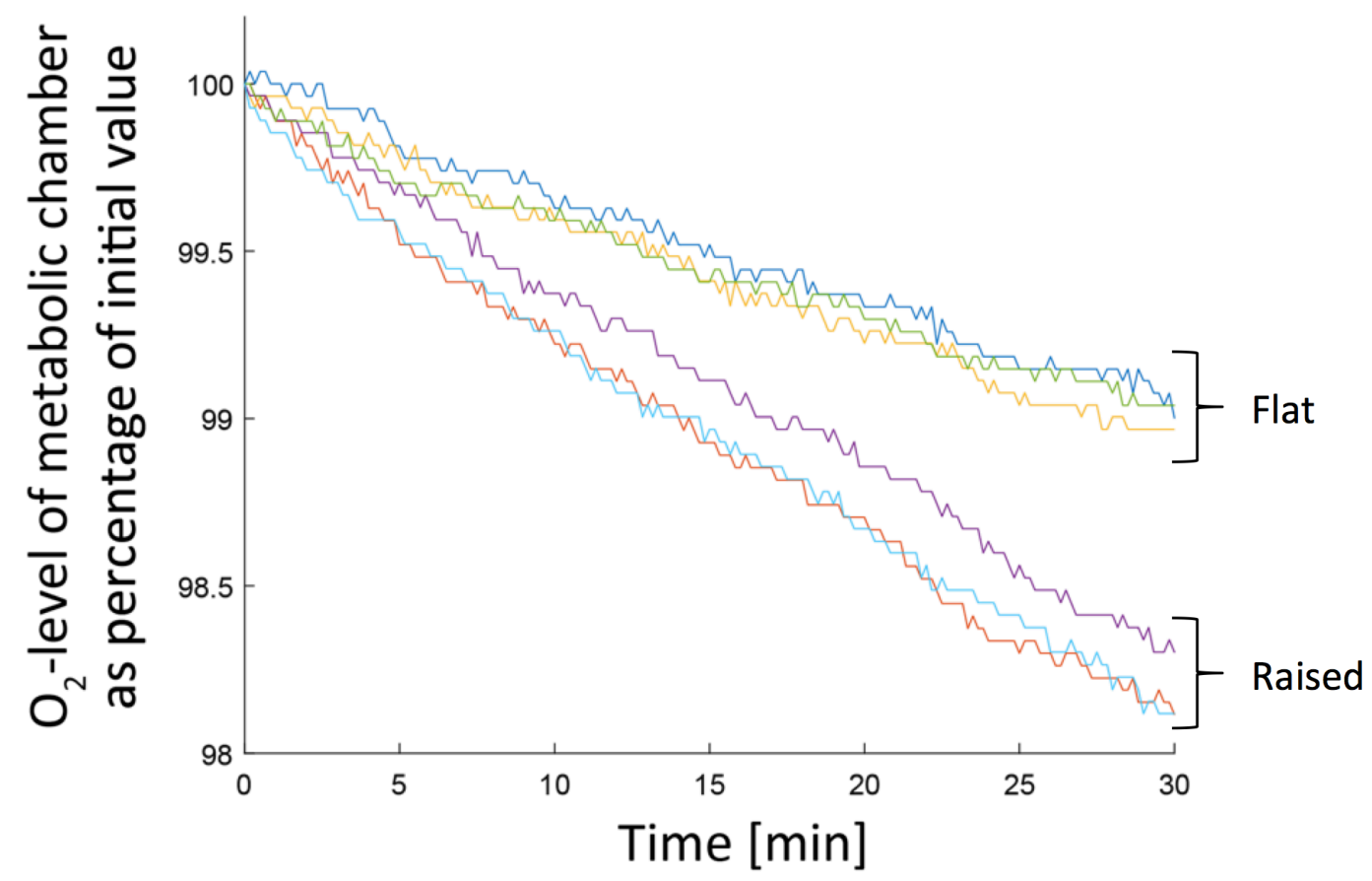

Figure 12 Oxygen consumption rates: flat vs. raised. One Xiphister was placed in a metabolic chamber kept at the constant temperature of $12^{\circ} \mathrm{C}$, either flat on its side or on a raised mesh surface, which allowed for air movement around the body. When lying on the concave surface, approximately half of the skin's surface area is not in contact with the air and therefore cannot be utilized for cutaneous respiration. Oxygen readings were taken every ten second for thirty minutes. When on the raised mesh surface, their oxygen consumption occurred at approximately twice the rate of when the fish was on the flat surface. Each trace is the result from one fish. ANCOVA results show that the slope variables are significantly different. $P<0.001$ 


\section{WATER TRANSPORT IN XIPHISTER MUCOSUS}

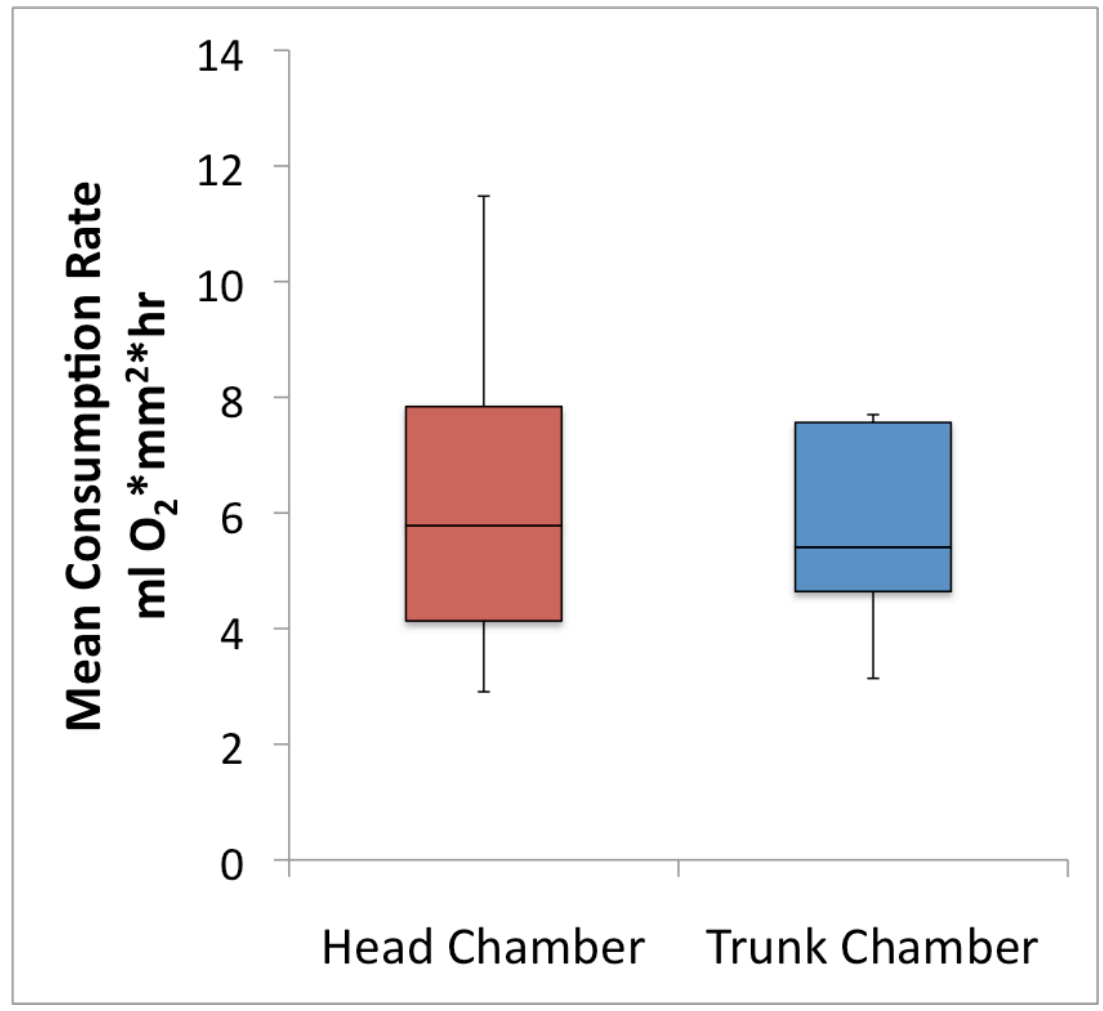

Figure 13 Oxygen consumption rates: head vs. trunk. Measurements of oxygen consumption per $\mathrm{mm}^{2}$ of Xiphister mucosus surface area in partitioned metabolic chamber. The ratio of trunk to head oxygen consumption rate is equal. $\mathbf{N}=\mathbf{9}$ 


\section{WATER TRANSPORT IN XIPHISTER MUCOSUS}

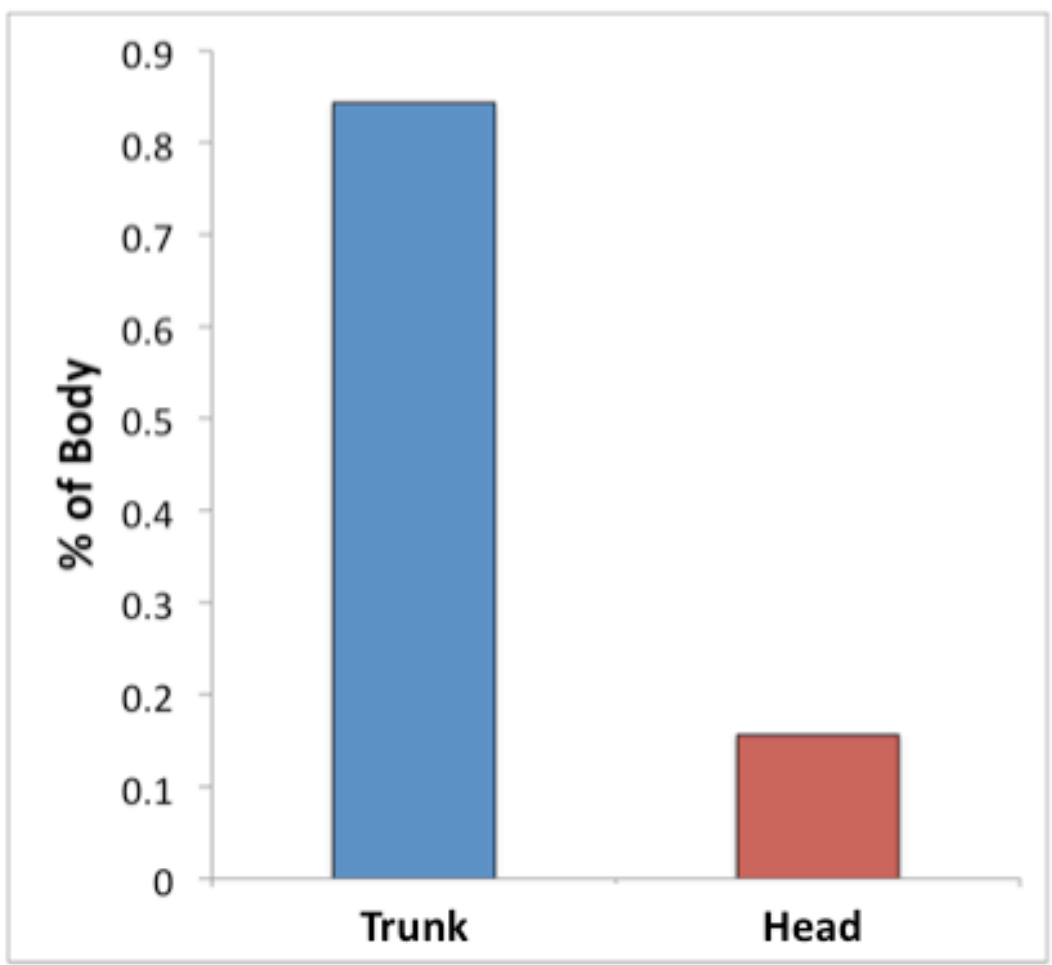

Figure 14 Body ratio: head vs. trunk. The ratio of trunk to head as positioned in our partitioned metabolic chamber is roughly that of six to one suggesting that despite an equal oxygen consumption rate per $\mathrm{mm}^{2}$ of skin, the much larger portion of the body accounts for $\approx 85 \%$ of aerial respiration in Xiphister mucosus. $\mathrm{N}=9$ 


\section{WATER TRANSPORT IN XIPHISTER MUCOSUS}

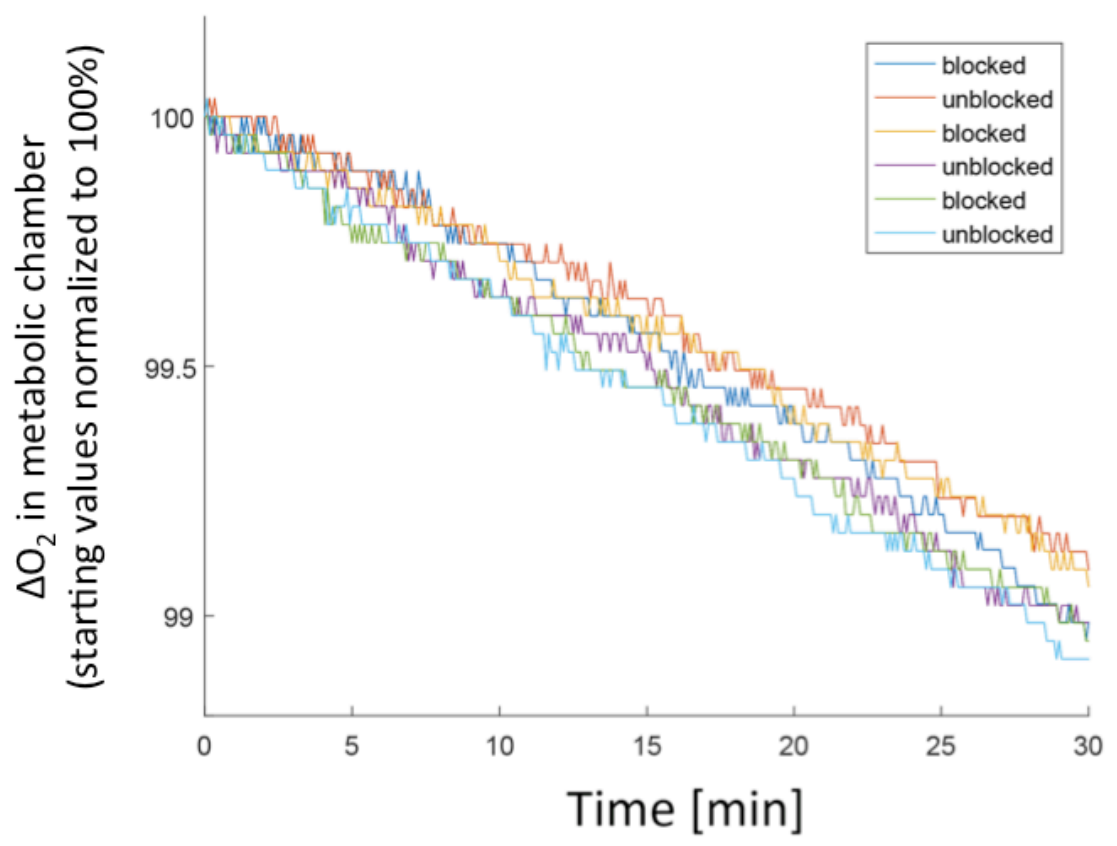

Figure 15 Oxygen consumption rates: blocked vs. unblocked. Xiphister, with a blocked or unblocked lateral line canal showed no significant difference in oxygen consumption. P > 0.5, N= 3 blocked, 3 unblocked 


\section{WATER TRANSPORT IN XIPHISTER MUCOSUS}

\section{Literature Cited}

Ali, M. A. (2013). Environmental physiology of fishes (Vol. 35). Springer Science \& Business Media.

Barton, M. (1985). Response of two species of amphibious stichaeoid fishes to temperature fluctuations in an intertidal habitat. Hydrobiologia, 120(2), 151-157.

Bleckmann, H., Tittel, G., \& Blübaum-Gronau, E. (1989). The lateral line system of surface-feeding fish: anatomy, physiology, and behavior. In The mechanosensory lateral line (pp. 501-526). Springer, New York, NY.

Bleckmann, H. (1986). Role of the lateral line in fish behaviour. In The behaviour of teleost fishes (pp. 177-202). Springer US.

Bleckmann, H., \& Münz, H. (1990). Physiology of lateral-line mechanoreceptors in a teleost with highly branched, multiple lateral lines. Brain, behavior and evolution, 35(4), 240-250.

Bleckmann, H., \& Zelick, R. (2009). Lateral line system of fish. Integrative zoology, 4(1), $13-25$.

Brett, J. R., \& Groves, T. D. D. (1979). Physiological energetics. Fish physiology, 8(6), 280-352.

Bridges, C. R. (1993). Ecophysiology of intertidal fish. Fish ecophysiology, 375-400.

Buckley, B. A., \& Hofmann, G. E. (2002). Thermal acclimation changes DNA-binding activity of heat shock factor 1 (HSF1) in the goby Gillichthys mirabilis: implications for plasticity in the heat-shock response in natural populations. Journal of Experimental Biology, 205(20), 3231-3240.

Coffin, A., Kelley, M., Manley, G. A., \& Popper, A. N. (2004). Evolution of sensory hair cells. In Evolution of the vertebrate auditory system (pp. 55-94). Springer New York.

Coombs, S., Görner, P., \& Münz, H. (Eds.). (2012). The mechanosensory lateral line: neurobiology and evolution. Springer Science \& Business Media.

Coombs, S., Janssen, J., \& Webb, J. F. (1988). Diversity of lateral line systems: evolutionary and functional considerations. In Sensory biology of aquatic animals (pp. 553-593). Springer, New York, NY. 


\section{WATER TRANSPORT IN XIPHISTER MUCOSUS}

Davenport, J., \& Woolmington, A. D. (1981). Behavioural responses of some rocky shore fish exposed to adverse environmental conditions. Marine \& Freshwater Behaviour \& Phy, 8(1), 1-12.

Daxboeck, C., \& Heming, T. A. (1982). Bimodal respiration in the intertidal fish, Xiphister atropurpureus (Kittlitz). Marine \& Freshwater Behaviour \& Phy, 9(1), 23-33.

Delaney, R. G., Lahiri, S., \& Fishman, A. P. (1974). Aestivation of the African lungfish Protopterus aethiopicus: cardiovascular and respiratory functions. Journal of Experimental Biology, 61(1), 111-128.

Denton, E. J., \& Gray, J. A. (1989). Some observations on the forces acting on neuromasts in fish lateral line canals. In The mechanosensory lateral line (pp. 229-246). Springer, New York, NY.

Dijkgraaf S (1963). The functioning and significance of the lateral-line organs. Biol Rev Camb Philos Soc 38, 51-105.

Doneen, B. A. (1976). Water and ion movements in the urinary bladder of the gobiid teleost Gillichthys mirabilis in response to prolactins and to cortisol. General and comparative endocrinology, 28(1), 33-41.

Eastman, J. T. (2017). Bathymetric distributions of notothenioid fishes. Polar Biology, 119.

Engelmann, J., Hanke, W., Mogdans, J., \& Bleckmann, H. (2000). Neurobiology: hydrodynamic stimuli and the fish lateral line. Nature, 408(6808), 51-52.

Eschmeyer, W. N., and Fong, J. (2017) Species by family/subfamily in the Catalog of fishes, electronic version (31 January 2017). San Francisco (California Academy of Sciences).

Evans, David H. "Sodium, chloride and water balance of the intertidal teleost, Xiphister atropurpureus." Journal of experimental Biology 47.3 (1967): 525-534.

Evans, David H. (David Hudson), 1940- \& Claiborne, James B (2006). The physiology of fishes (3rd ed). Taylor\&Francis, Boca Raton, FL 


\section{WATER TRANSPORT IN XIPHISTER MUCOSUS}

Feder, M. E., \& Burggren, W. W. (1985). Cutaneous gas exchange in vertebrates: design, patterns, control and implications. Biological Reviews, 60(1), 1-45.

Flock, A. (1964). Electron microscopic and electrophysiological studies on the lateral line canal organ. Acta oto-laryngologica. Supplementum, SUPPL-199.

Glover, Chris N., Carol Bucking, and Chris M. Wood. "The skin of fish as a transport epithelium: a review." Journal of Comparative Physiology B 183.7 (2013): 877-891.

Gracey, A. Y., Troll, J. V., \& Somero, G. N. (2001). Hypoxia-induced gene expression profiling in the euryoxic fish Gillichthys mirabilis. Proceedings of the National Academy of Sciences, 98(4), 1993-1998.

Graham, J. B. (Ed.). (1997). Air-breathing fishes: evolution, diversity, and adaptation. Academic Press.

Graham, J. B., \& Lee, H. J. (2004). Breathing air in air: in what ways might extant amphibious fish biology relate to prevailing concepts about early tetrapods, the evolution of vertebrate air breathing, and the vertebrate land transition?. Physiological and Biochemical Zoology, 77(5), 720-731.

Gray, J. (1984). Interaction of sound pressure and particle acceleration in the excitation of the lateral-line neuromasts of sprats. Proceedings of the Royal Society of London B:

Biological Sciences, 220(1220), 299-325.

Gunther, A. (1861). Catalogue of the Acanthopterygian fishes in the collection of the British museum. London: Order of the Trustees.

Haynes, T. B., Phillips-Mentzos, E., \& Facey, D. E. (2009). A comparison of the hyposaline tolerances of black prickleback (Xiphister atropurpureus) and penpoint gunnel (Apodichthys flavidus). Northwest Science, 83(4), 361-366.

Hazel, J. R. (1995). Thermal adaptation in biological membranes: is homeoviscous adaptation the explanation?. Annual review of physiology, 57(1), 19-42.

Hill, R. W., Wyse, G. A., Anderson, M., \& Anderson, M. (2004). Animal physiology (Vol. 2). Massachusetts: Sinauer Associates. 


\section{WATER TRANSPORT IN XIPHISTER MUCOSUS}

Hoese, G., Addison, A., Toulkeridis, T., \& Toomey III, R. (2015). Observation of the Catfish Chaetostoma microps Climbing in a Cave in Tena, Ecuador. Subterranean Biology, 15, 29.

Hofmann, G. E., Buckley, B. A., Airaksinen, S., Keen, J. E., \& Somero, G. N. (2000). Heat-shock protein expression is absent in the antarctic fish Trematomus bernacchii (family Nototheniidae). Journal of Experimental Biology, 203(15), 2331-2339.

Horn, M., Martin, K., and Chotkowski, M. (1999). Intertidal Fishes - Life in Two Worlds. Elsevier.

Horn, M. and Riegle, K. (1981). Evaporative water loss and intertidal ver- tical distribution in relation to body size and morphology of stichaeoid fishes from california. Journal of Experimental Marine Biology and Ecol- ogy, 50:273-288.

Janssen, J. (1997). Comparison of response distance to prey via the lateral line in the ruffe and yellow perch. Journal of Fish Biology, 51(5), 921-930.

Janssen, J. (2004). Lateral line sensory ecology (pp. 231-264). New Delhi: Narosa Publishing House.

Jeffery, W. R., Strickler, A. G., \& Yamamoto, Y. (2003). To see or not to see: evolution of eye degeneration in Mexican blind cavefish. Integrative and Comparative Biology, 43(4), 531-541.

Kaldenbach, F. (2016). Natural and artificial lateral lines: Form-function relationship and Detection of water surface waves (doctoral dissertation). University of Bönn, Bönn, Germany

Kelly, J. P., \& van Netten, S. M. (1991). Topography and mechanics of the cupula in the fish lateral line. I. Variation of cupular structure and composition in three dimensions. Journal of morphology, 207(1), 23-36.

Klein, A. T., \& Bleckmann, H. (2012). Lateral Line Canal Morphology and Noise Reduction. In The Effects of Noise on Aquatic Life (pp. 121-123). Springer, New York, NY.

Klein, A., Münz, H., \& Bleckmann, H. (2013). The functional significance of lateral line canal morphology on the trunk of the marine teleost Xiphister atropurpureus (Stichaeidae). Journal of comparative physiology A, 199(9), 735-749. 


\section{WATER TRANSPORT IN XIPHISTER MUCOSUS}

Klein, A., \& Bleckmann, H. (2015). Function of lateral line canal morphology. Integrative zoology, 10(1), 111-121.

Konishi, T., Hamrick, P. E., \& Walsh, P. J. (1978). Ion transport in guinea pig cochlea: I. Potassium and sodium transport. Acta oto-laryngologica, 86(1-6), 22-34.

Kottelat, M. (2012). Conspectus cobitidum: an inventory of the loaches of the world (Teleostei: Cypriniformes: Cobitoidei). Raffles Bulletin of Zoology.

Linley, T. D., Gerringer, M. E., Yancey, P. H., Drazen, J. C., Weinstock, C. L., \& Jamieson, A. J. (2016). Fishes of the hadal zone including new species, in situ observations and depth records of Liparidae. Deep Sea Research Part I: Oceanographic Research Papers, 114, 99-110.

Makushok, V. M. (1961). Some peculiarities in the structure of the seismosensory system of the northern blenniids (Stichaeoidae, Blennioidei, Pisces). US Bureau of Commercial Fisheries.

Martin, K. L. (1995). Time and tide wait for no fish: intertidal fishes out of water. In Ecomorphology of fishes (pp. 165-181). Springer Netherlands.

Martin, K. L. (1993). Aerial release of CO 2 and respiratory exchange ratio in intertidal fishes out of water. Environmental biology of fishes, 37(2), 189-196.

McCormick, C. A. (1989). Central lateral line mechanosensory pathways in bony fish. In The Mechanosensory Lateral Line (pp. 341-364). Springer, New York, NY.

Mecklenburg, C. W., Mecklenburg, T. A., \& Thorsteinson, L. K. (2002). Fishes of Alaska. Montgomery, J., Carton, G., Voigt, R., Baker, C., \& Diebel, C. (2000). Sensory processing of water currents by fishes. Philosophical Transactions of the Royal Society of London B: Biological Sciences, 355(1401), 1325-1327.

Montgomery, J., Coombs, S., \& Halstead, M. (1995). Biology of the mechanosensory lateral line in fishes. Reviews in Fish Biology and Fisheries, 5(4), 399-416.

Münz, H. (1989). Functional organization of the lateral line periphery. In The mechanosensory lateral line (pp. 285-297). Springer New York. 


\section{WATER TRANSPORT IN XIPHISTER MUCOSUS}

Nelson, J. S., Grande, T. C., \& Wilson, M. V. (2016). Fishes of the World. John Wiley \& Sons.

Northcutt, R. G., \& Gans, C. (1983). The genesis of neural crest and epidermal placodes: a reinterpretation of vertebrate origins. The Quarterly review of biology, 58(1), 1-28.

Northcutt, R. G. (1989). The phylogenetic distribution and innervation of craniate mechanoreceptive lateral lines. In The mechanosensory lateral line (pp. 17-78). Springer, New York, NY.

Northcutt, R. G. (2002). Understanding vertebrate brain evolution. Integrative and comparative biology, 42(4), 743-756.

Park, B. Y., \& Saint-Jeannet, J. P. (2010, July). Induction and segregation of the vertebrate cranial placodes. In Colloquium series on developmental biology (Vol. 1, No. 1, pp. 1-83). Morgan \& Claypool Life Sciences.

Podrabsky, J. E., Carpenter, J. F., \& Hand, S. C. (2001). Survival of water stress in annual fish embryos: dehydration avoidance and egg envelope amyloid fibers. American Journal of Physiology-Regulatory, Integrative and Comparative Physiology, 280(1), R123-R131.

Peden, Alex E. "Reexamination of two species in the stichaeid genus, Anoplarchus." Copeia (1966): 340-345.

Peppar, J. L. (1965). Some features of the life history of the cockscomb prickleback: Anoplaruchus purpurescens Gill (Doctoral dissertation, University of British Columbia).

Peterson, Roger Tory, William N. Eschmeyer, and Earl S. Herald. A field guide to Pacific coast fishes: North America. Houghton Mifflin Harcourt, 1999.

Podrabsky, J. E., \& Hand, S. C. (1999). The bioenergetics of embryonic diapause in an annual killifish, Austrofundulus limnaeus. Journal of Experimental Biology, 202(19), 2567-2580.

Podrabsky, J. E., Tingaud-Sequeira, A., \& Cerdà, J. (2010). Metabolic dormancy and responses to environmental desiccation in fish embryos. In Dormancy and resistance in harsh environments (pp. 203-226). Springer Berlin Heidelberg. 


\section{WATER TRANSPORT IN XIPHISTER MUCOSUS}

Radchenko, O. A., Chereshnev, I. A., \& Petrovskaya, A. V. (2014). Genetic

differentiation of species and taxonomic structure of the superfamily Stichaeoidea (Perciformes: Zoarcoidei). Russ. J. Mar. Biol, 40(6), 473-485.

Randall, D. J. (1970). 7 Gas Exchange in Fish. Fish physiology, 4, 253-292.

Randall, D. J. (1981). The evolution of air breathing in vertebrates. Cambridge University Press.

Reno, H. W., Gehlbach, F. R., \& Turner, R. A. (1972). Skin and aestivational cocoon of the aquatic amphibian, Siren intermedia Le Conte. Copeia, 625-631.

Romer, A. S. (1967). Major steps in vertebrate evolution. Science, 158(3809), 1629-1637.

Russell, I. J., \& Sellick, P. M. (1976). Measurement of potassium and chloride ion concentrations in the cupulae of the lateral lines of Xenopus laevis. The Journal of physiology, 257(1), 245-255.

Schwartz, E. (1974). Lateral-line mechano-receptors in fishes and amphibians. In Electroreceptors and Other Specialized Receptors in Lower Vertrebrates (pp. 257-278). Springer Berlin Heidelberg.

Schwassmann, H. O., \& Kruger, L. (1965). Experimental analysis of the visual system of the four-eyed fish Anableps microlepis. Vision Research, 5(6), 269-IN1.

Sideleva, V. G. (1996). Comparative character of the deep-water and inshore cottoid fishes endemic to Lake Baikal. Journal of fish biology, 49(sA), 192-206.

Sivak, J. G. (1976). Optics of the eye of the "four-eyed fish"(Anableps anableps). Vision Research, 16(5), 531-IN6.

Smith, C. U. M. (2008). Biology of sensory systems. John Wiley \& Sons.

Stephenson, T. A., \& Stephenson, A. (1950). Life between tide-marks in North America: the Florida Keys. The Journal of Ecology, 354-402.

Teal, J. M., \& Carey, F. G. (1967). Skin respiration and oxygen debt in the mudskipper Periopthalmus sobrinus. Copeia, 1967(3), 677-679.

Karleskint, G., Turner, R., \& Small, J. (2012). Introduction to marine biology. Cengage Learning. 


\section{WATER TRANSPORT IN XIPHISTER MUCOSUS}

Vidthayanon, C., \& Jaruthanin, K. (2002). Schistura kaysonei,(Teleostei: Balitoridae) a new cave fish from the Khammouan karst, Laos PDR. Aqua, Journal of Ichthyology and Aquatic Biology, 6(1), 17-20.

Webb, J. F. (1989). Gross Morphology and Evolution of the Mechanoreceptive LateralLine System in Teleost Fishes (Part 1 of 2). Brain, behavior and evolution, 33(1), 34-43.

Webb, J. F. (1989). Developmental constraints and evolution of the lateral line system in teleost fishes. In The Mechanosensory Lateral Line (pp. 79-97). Springer, New York, NY.

Webb, J. F. (2013). Morphological diversity, development, and evolution of the mechanosensory lateral line system. In The lateral line system (pp. 17-72). Springer New York.

Wiley, E. O. (2010). A teleost classification based on monophyletic groups. Origin and phylogenetic interrelationships of teleosts, 123-182.

Wonsettler, A. L., \& Webb, J. F. (1997). Morphology and development of the multiple lateral line canals on the trunk in two species of Hexagrammos (Scorpaeniformes, Hexagrammidae). Journal of Morphology, 233(3), 195-214.

Wood, C. M., Brix, K. V., De Boeck, G., Bergman, H. L., Bianchini, A., Bianchini, L. F., ... \& Letura, K. M. (2016). Mammalian metabolic rates in the hottest fish on earth. Scientific reports, 6, 26990.

Wootton, R. J. (2012). Ecology of teleost fishes (Vol. 1). Springer Science \& Business Media.

Yamanaka, Y., Nakae, M., Fukuda, E., \& Sasaki, K. (2010). Monophyletic origin of the dorsally arched lateral line in Teleostei: evidence from nerve innervation patterns. Ichthyological research, 57(1), 49-61.

Zander, C. D. (1972). Beziehungen zwischen Körperbau und Lebensweise bei Blenniidae (Pisces) des Roten Meeres. Zoomorphology, 71(4), 299-327. 